\title{
A Market Test for Race Discrimination in Bail Setting
}

\author{
Ian Ayres* \& Joel Waldfogel**
}

\begin{abstract}
Regression analysis, a common method of attempting to demonstrate racial and gender discrimination in hiring and other contexts, suffers from a number of shortcomings that invariably cast doubt on any incriminating results it produces. Most notably, regression models may fail to account for variables which correlate both with legitimate goals of a decisionmaker and with racel gender categories. In this article, Professors Ayres and Waldfogel offer an alternative method of measuring discrimination that overcomes the limitations of traditional regression tests. The authors present a market-based test of unjustified disparate impact using data from the bail bond market in New Haven, Connecticut, to demonstrate that New Haven courts systematically "overdeter" black and male Hispanic defendants from fleeing after release on bail by setting bail at seemingly unjustified high levels for these groups. Professors Ayres and Waldfogel discuss the validity of the assumptions underlying their model, and of possible nondiscriminatory explanations for their finding of disparate impact. They also offer suggestions for application of their methodology in contexts other than bail setting.
\end{abstract}

INTRODUCTION ........................................

I. A Theory of Bond Dealers, Defendants, and Court Behavior ........................................ 995

A. Institutional Features of Connecticut Bail Setting .......... 995

B. Determinants of Bond Dealers' Fees in a Competitive Market............................................ 997

C. Determinants of Bail Amount ........................ 1001

II. Testing the Theory ................................. 1004

A. A Description of the Bailbonding Data................. 1004

B. Evidence of Market Competition ...................... 1004

C. A Market Test for Discrimination in Bail Setting........... 1008

* Professor, Stanford Law School.

** Assistant Professor, Department of Economics, Yale University; Olin Visiting Fellow, Yale Law School; Faculty Research Fellow, National Bureau of Economic Research. We are grateful to Jennifer Arlen, John Caskey, Morgan Cloud, John Donohue, Robert Frank, Mark Kelman, Dan Kessler, Stephen Marks, Dan Rubinfeld, Ken Scott, Joe Tracy, Deborah Young, and seminar participants at Boston University, Chicago, Emory, Harvard, Kansas, Oregon, Stanford, Toronto, and UCLA law schools and the Yale economics department for helpful suggestions. Support from the National Science Foundation under grant SBR-9310526, the Yale Initiative on Poverty and Law, the John M. Olin Program in Law and Economics, and the Roberts Center for Law, Business and Corporate Governance is gratefully acknowledged. Dan Ackerberg, Todd Cleary, Ravi Pherwany, and Cathy Sharkey provided excellent research assistance. 
D. The Price of Pretrial Freedom .................... 1013

E. Estimating the Extent of Discrimination in Bail Setting ....... 1014

III. NoNDISCRIMINATORY EXPLANATIONS .................... 1015

A. Market Forces that Might Cause Bond Rates not to Reflect

Flight Probabilities ............................ 1016

1. Price discrimination ......................... 1017

2. Dealer search and monitoring costs ................. 1019

3. Forfeiture rates .............................. 1019

4. Collateral ..................................... 1020

5. Fixed costs ................................. 1021

B. Alternative Judicial Goals........................ 1022

1. Targeting higher probabilities of appearance for more serious offenses ............................... 1023

2. Color-blind bail setting......................... 1026

3. Deterring pretrial misconduct ................. 1028

4. Targeting desired bond fee instead of desired probability of appearance ................................. 1029

C. Sample Selection ............................ 1031

1. Defendants who remain in jail ................... 1033

2. Posting bail personally ....................... 1035

IV. Harnessing the Market in the Bail Setting Process ....... 1037

Conclusion ...................................... 1038

Appendix A: Ex Ante Monitoring and Ex Post Search ......... 1042

A. Demonstrating How Monitoring and Search Can Deter

Flight...................................... 1042

B. Investigating the Effects of Monitoring and Search Costs on

the Bail Rate ................................... 1043

APPENDIX B: Estimating RAte SCHEdules ................. 1044

\section{INTRODUCTION}

[T] he professional bondsman system ... is odious at best. The effect of such a system is that the professional bondsmen hold the keys to the jail in their pockets. ${ }^{1}$

These words of Judge Skelly Wright capture the disdain often shown to bail bond dealers. ${ }^{2}$ Bail bond dealers are widely thought to be corrupt and to assert too much control over pretrial release decisions. ${ }^{3}$ Commentators

1. Pannell v. United States, 320 F.2d 698, 699 (D.C. Cir. 1963) (Wright, J., concurring).

2. We have chosen to refer to the people who post bail bonds as "bond dealers" instead of the more prevalent term "bondsmen," in part because we believe that language not only describes the world (in our data, all persons providing this service were male), but also establishes normative categories.

3. Ronald Goldfarb's characterization is typical:

Many, too many, agents are undesirable persons, former felons, and generally repugnant characters. Some bondsmen are colorful Runyonesque characters. Some are legitimate businessmen. But too many are "low-lifes" whose very presence contaminates the judicial process. ... [V]ery frequently, if not generally, the bail bondsman is an unappealing and useless member of society. 
offering bail reform proposals often advocate eliminating private bail bonding entirely. ${ }^{4}$

This article suggests, however, that the bail bond market may have an unforeseen usefulness. If competition induces bond dealers to charge fees equal to their average costs, the pricing behavior of bond dealers can be used to assess whether states discriminate on the basis of race or gender in setting bail. This article uses empirical evidence from the bail bond market in Connecticut to evaluate the determinants of bail setting. 5

Connecticut law has traditionally mandated that bail be set at the smallest amount that will "reasonably assure the appearance of the arrested person in court."6 Implicit in this statutory command is the notion that higher bail tends to reduce the probability that a defendant will disappear. If the defendant posts bail herself, the potential forfeiture of the bail gives the defendant a direct financial incentive to appear at trial. If the defendant contracts with a bond dealer, however, the incentive to appear is indirect. A bond dealer charges the defendant a nonrefundable fee, and in return assumes the risk of paying the bail amount to the state should the defendant flee. Because the bond dealer's fee is

Ronald Goldfarb, Ransom: A Critique of the American Bail System 101-02 (1965); see also Arthur L. Beeley, The Bail System In Chicago 40 (1927) ("The moral standards of these bondrunners and their agents are very low."); The Cleveland Foundation, Criminal Justice in CleveLAND (Roscoe Pound \& Felix Frankfurter eds., 1922) (identifying the real evil in bail bonding as disreputable professional bond dealers who exploit the poor and prostitute the administration of justice); Daniel J. Freed \& Patricia M. Wald, Batl. in the United States: 1964, at 34 (National Conference on Bail and Criminal Justice Working Paper) ("Regular payoffs by bondsmen to police have sometimes been described as essential to survival in the bonding business."); JoHN S. GoldKamp \& Michael R. Gottrredson, Policy Guidelines for Bail: AN Experiment in Court Reform 18 (1985) ("[B]ondsmen seemed to invite corruption of jailors, police, and judges."); Charles E. Ares, Anne Rankin \& Herbert Sturz, The Manhattan Bail Project: An Interim Report on the Use of Pre-Trial Parole, 38 N.Y.U. L. Rev. 67, 67 (1963) ("[T]he final decision as to whether a defendant is to be kept in jail usually rests in the hands of the professional bondsman ....").

4. The American Bar Association concludes, for example, that "[r]eliance on money bail should be reduced to minimal proportions" and that "[c]ompensated sureties should be abolished." American Bar Association, Standards Relating to Pretrial Release \$ 1.2(c), quoted in State of Connecticut, Pretrial Comimission, Report of the Connecticut Pretrial Commission to the General AssemBLY 34 (1981).

5. Existing empirical research on bail setting typically either focuses directly on the determinants of bail setting or analyzes the impact of bail on flight and pretrial crime. For examples of bail analyses, see GoldKAMP \& GotTrRedson, supra note 3; John S. Goldkamp, Questioning the Practice of Pretrial Detention: Some Empirical Evidence from Philadelphia, 74 J. CRIM. L. \& CRIminology 1556 (1983); William M. Landes, Legality and Reality: Some Evidence on Criminal Procedure, 3 J. LegaL STud. 287 (1974); Ilene H. Nagel, The LegaVExtra-Legal Controversy: Judicial Decisions in Pretrial Release, 17 L. \& Soc'y Rev. 481 (1983). See also Samuel L. Myers, Jr., The Economics of Bail Jumping, $10 \mathrm{~J}$. LeGAL Stud. 381 (1981) (providing an analysis of bail jumping).

6. Conn. Gen. Stat. Ann. § 54-64a (1985 \& West Supp. 1993); cf. Freed \& WaLd, supra note 3 , at 8 (generalizing that "bail in America has developed for a single lawful purpose: to release the accused with assurance that he will retum at trial"). In Connecticut, bail traditionally could not be used to prevent suspects from committing pretrial crimes. If the prosecution believed "there exist[ed] a danger that the defendant $w[$ ould] commit a serious crime, or w[ould] seek to intimidate witnesses, or w[ould] otherwise unlawfully interfere with the orderly administration of justice," it had to petition the court separately to additionally restrict pretrial release. Conn. Ct. R. § 667 (1990). Recently, the Connecticut statute has been amended to allow courts to set bail amounts designed to reasonably assure "that the safety of . . . other person[s] will not be endangered." ConN. Gen. STAT. ANn. § 54-64a(b) (West Supp. 1993) (effective 1990). See note 60 infra for a more detailed discussion of this amendment. In future research, we plan to investigate whether this revision has affected how courts set bail. 
nonrefundable and therefore is a "sunk cost," the size of the fee should not affect the likelihood of the defendant's appearance. ${ }^{7}$ Nevertheless, a higher bail amount can reduce the probability of flight: A higher bail amount credibly commits the bond dealer to expend more resources on (1) monitoring the defendant's whereabouts before a scheduled appearance; and (2) searching to reapprehend any defendant who flees. ${ }^{8}$ Thus, if a defendant fails to appear, a bond dealer with $\$ 20,000$ at risk would likely search more extensively than a bond dealer with only $\$ 2000$ at risk. Anticipating bond dealers' incentive to monitor and search more aggressively, defendants might perceive a lower likelihood of successful flight when the court sets a high bail amount.9 Even when defendants use bond dealers to secure release, high bail amounts can thus reduce the probability of successful flight and even deter flight attempts. Connecticut courts can "reasonably assure the appearance" of defendants by setting bail amounts high enough to reduce the defendants' flight probability to an acceptable level. ${ }^{10}$

Bail setting in Connecticut has come under fire recently amid allegations of racial bias. In 1991, the Hartford Courant reported that bail amounts for black defendants were, on average, more than 70 percent higher than for white defendants. ${ }^{11}$ Reports such as this are consistent with prior evidence of race dis-

7. Commentators have reasoned that the nonrefundable nature of bond dealer fees counteracts any possible deterrent value of bail:

[I]t was strongly argued [by critics of the bail system] that use of the bondsman defeated the rationale that defendants released on cash bail would have an incentive to retum. Any deterrent value associated with the use of financial bail to protect against possible defendant flight was seen to be destroyed when defendants lost the fee paid to the bondsman whether or not they returned to court.

GoldKAMP \& GotTrRedson, supra note 3, at 19; see also Pannell v. United States, 320 F.2d 698, 702 (D.C. Cir. 1963) (Bazelon, C.J., concurring in part and dissenting in part) ("If [the bond dealer] does not [require collateral], then appellant has no real financial stake in complying with the conditions of the bond, regardless of the amount, since the fee paid for the bond is not refundable under any circumstances.").

8. Indeed, bond dealers can exercise "power over an accused [that] may exceed the power of the state." Note, Bailbondsmen and the Fugitive Accused -The Need for Formal Removal Procedures, 73 YALE L.J. 1098, 1100 (1964). For example, bond dealers "may seize the accused in a foreign jurisdiction without the slightest compliance with extradition requirements in the foreign jurisdiction." Id; see also FREED \& WALD, supra note 3, at 22 ("As a bailor, [a bond dealer] enjoys a private power to arrest his bailee. He can even surrender him to the court before trial if he suspects that flight is imminent.").

9. Commentators have been divided over whether, as an empirical matter, higher bail amounts deter flight when the defendant uses a bail bond dealer. Compare Landes, supra note 5, at 320-25 (finding deterrence effect) and Caleb Foote, Compelling Appearance in Court: Administration of Bail in Philadelphia, 102 U. PA. L. Rev. 1031, 1066-67 (1954) (finding deterrence effect likely) with Stevens H. Clarke, Jean L. Freeman \& Gary G. Koch, Bail Risk: A Multivariate Analysis, 5 J. LEGAL STUd. 341, 375 (1976) (finding that "cash bond releasees probably differed little from bondsmen releasees with regard to actual rates of nonappearance"). Using bail bonding data, this paper independently concludes that higher bail amounts deter pretrial flight. See note 108 infra and accompanying text.

High bail amounts may also deter flight if bond dealers require defendants with higher bail to post more personal collateral. The prospect of forfeiting personal belongings would create the same flight deterrence as directly posting bail. We examine the effect of collateral at notes 119-122 infra and accompanying text.

10. Implicit in this statement is the assumption that those who set bail disregard the rates set by bond dealers. For arguments justifying this point, see notes 66-68 infra and accompanying text.

11. Brant Houston \& Jack Ewing, Blacks and Hispanics Must Pay More to Get Out of Jail, HarTFORD COURANT, June 16, 1991, at A1. 
crimination in Connecticut ${ }^{12}$ and in other states. ${ }^{13}$ For example, Malcolm Feeley's classic analysis of the New Haven Court of Common Pleas found that black defendants were more often subject to monetary bail and were less likely to flee when released on bail than were white defendants. ${ }^{14}$

Nevertheless, providing unequivocal evidence of racial discrimination in bail setting has proven elusive to scholars and lawyers alike. The traditional way to statistically test for discrimination in bail setting would be to estimate in a regression how permissible factors (those related to a defendant's flight risk) affect the size of bail, and then to determine whether, after controlling for these

12. See, e.g., Noreen L. Channels \& Sharon Hertzberger, The Effects of Offender Characteristics on Progress Through the Criminal Justice System (May 1988) (unpublished manuscript, on file with the Stanford Law Review) (concluding from 1983-1984 Connecticut bail commission interviews that blacks and Hispanics were more likely to be required to post bail and more likely to receive higher bail amounts); Justice Education Center, Court Disposition Study: Criminal Offenders in Connecticut's Courts in 1991 (1993) (unpublished manuscript, on file with the Stanford Law Review) (Latinos and African-Americans are more likely than whites to receive bail); Catherine M. Sharkey, The Economics of the Bail System in New Haven: An Examination of Judicial Bail Setting and the Market for Bail Bonds 27-30 (Apr. 1992) (unpublished manuscript, on file with the Stanford Law Review) (finding that, after controlling for measures of community ties and offense severity, race has a significant effect on bail amounts in Connecticut). But see Mwangi S. Kimenyi, Thomas J. Miceli \& Subhash C. Ray, Race and Justice: An Economic Analysis of the Bail System (April 1993) (unpublished manuscript on file with the Stanford Law Review) (finding that racial discrimination in bail setting is due to imperfect information rather than prejudice).

13. Empirical evidence of race discrimination has been documented in New York state, see 2 New York State Judicial Commission on Minorities, Report 141-55 (1991); Florida, see Florida Supreme Court Raclal and Ethnic Bias Study Commission, Where the InJured Fly for Justice (1991); and New Jersey, see New Jersey Supreme Court Task Force on Minorities, Interim RePORT (1989).

Anecdotal evidence of race discrimination has also been reported by academics. See Freed \& WALD, supra note 3, at 33 (citing reported difficulties of Puerto Ricans and civil rights demonstrators as evidence that bond dealers may refuse to post bail for unpopular minority groups); GoLDFARB, supra note 3, at 84-85 ("[]]t is fairly common knowledge that bondsmen in various cities were subject to severe pressures against writing bonds for persons arrested during civil rights protests during the last decade."). But see James Eisenstenn \& Herbert JacoB, Felony Justice: AN ORganizational ANalYSIS OF CRIMINAL COURTS 199 (1977) ("In [Chicago, Detroit, and Baltimore], when bonds rather than personal recognizance were required, the offense charged was more important in determining the bail amount than the defendant's race, his police record, the kind of attomey (if any), or the courtroom workgroup that processed his case."); Nagel, supra note 5, at 506 ("The defendant's race has no effect on the decision to release on recognizance and small effects on the bail amount decision and on the decision to offer a cash alternative.").

14. Malcolm M. Feeley, The Process Is the Punishment: Handling Cases in a Lower CRIMINAL CourT (1979). In a multivariate regression, Feeley found that blacks were $15 \%$ more likely than whites to be required to post bail but were $6 \%$ less likely to flee. Id. at 207, 231. Even though the first result was statistically significant at the $95 \%$ confidence level, Feeley concluded that these results did not support a finding of significant discrimination:

[A]s suggested here, there is some evidence to support charges of racial discrimination. On the whole, however, no strong evidence demonstrates any significant or even measurable amount of racial discrimination in outcomes. The fast pace and standardized routines of the court probably minimize the importance of race. But offhand racial slurs by court personnel are occasionally overheard in courtroom and conidors; and it is these remarks, coupled with the disproportionately high numbers of Black defendants in an otherwise "white" courtroom, that give the impression of pervasive racial discrimination by the court. This belief is widespread among Blacks and many whites. Here court personnel are more guilty of fostering the appearance of discrimination than of fostering its actual practice.

Id. at 312 n.10. Feeley's analysis of race discrimination in New Haven in 1973 is particularly relevant to our study because our data comes from the same court. 
permissible factors, race is still a significant determinant of the bail amount. ${ }^{15}$ Despite its popularity, this methodology is dogged by the problem of "omitted variable bias": Race may be correlated with unobserved variables that are not controlled for in the regression, but that legitimately increase bail size. If this is the case, the race effects estimated by regression analysis might not be caused by disparate racial treatment.

For example, our analysis of 1118 New Haven arrests reveals that after controlling for eleven variables relating to the severity of the alleged offense, bail amounts set for black male defendants were 35 percent higher than those set for their white male counterparts. ${ }^{16}$ By itself, this result does not constitute very powerful evidence of race discrimination because the regression does not control for many other variables that might explain the racial disparity. For example, black male defendants might be less likely to be employed or to have other community ties, which might justify a higher bail amount. ${ }^{17}$ Judges might have set higher bail for black male defendants not because they were black, but because other characteristics we did not observe indicated that these defendants had a higher propensity to flee.

The omitted variable problem has made it exceedingly difficult to use regression analysis to demonstrate racial discrimination. ${ }^{18}$ For example, in $M c$ Cleskey v. Kemp ${ }^{19}$ the Supreme Court rejected a regression study that, after controlling for 230 variables, indicated that black defendants charged with kill-

15. For further discussion of the use of regression analysis to prove discrimination, see Thomas J. Campbell, Regression Analysis in Title VII Cases: Minimum Standards, Comparable Worth, and Other Issues Where Law and Statistics Meet, 36 STAN. L. REv. 1299 (1984). Another traditional test of race discrimination is the "audit" methodology often used in fair housing studies, whereby auditors who are identical except for race attempt to rent an apartment or purchase a car. See Ian Ayres, Fair Driving: Gender and Race Discrimination in Retail Car Negotiations, 104 HARv. L. Rev. 817 (1991); Ian Ayres \& Peter Siegelman, Race and Gender Discrimination in Bargaining for a New Car, 84 AM. Econ. Rev. (forthcoming 1994); James J. Heckman \& Peter Siegelman, The Urban Institute Audit Studies: Their Methods and Findings, in Clear and Convincing Evidence: Measurement of Discrimination in AMERICA 187 (Michael Fix \& Raymond Struyk eds., 1993); John Yinger, Measuring Racial Discrimination with Fair Housing Audits: Caught in the Act, 76 AM. Econ. REv. 881 (1986). In regression methodology, the researcher attempts to control for differences among racial groups after the fact (that is, after the potentially discriminatory treatment has taken place), whereas in audit methodology, the researcher attempts to eliminate differences among racial groups before collecting data.

16. See notes 79-86 infra and accompanying text.

17. Alternatively, one might argue that the courts rationally infer from statistical information that black defendants were more likely to flee and thus required higher bail. Each of these two explanations for racial disparity (omitted variables and statistical discrimination) turns on what kinds of information may be observed and who is able to observe them. The omitted variable explanation posits that courts and bond dealers observe variables that we did not account for. The statistical discrimination theory suggests that courts use race as a proxy for variables related to flight but unobservable to either the courts, the bond dealers, or to us.

These two explanations for the racial disparity have very different legal significance: If the racial disparity is caused by omitted variables then the bail setters are not discriminating on the basis of race. But statistical discrimination (even if based on valid statistical inferences) would constitute disparate racial treatment and would violate the Equal Protection Clause unless the state could show under the strict scrutiny test that the disparate treatment furthered a compelling state interest.

18. See Campbell, supra note 15, at 1305-12 (suggesting that "goodness-of-fit" measures can be used to evaluate whether relevant variables have been omitted); Michael O. Finkelstein, The Judicial Reception of Multiple Regression Studies in Race and Sex Discrimination Cases, 80 Colum. L. Rev. $737,742-45$ (1980) (discussing the exclusion of relevant job qualification variables).

19. 481 U.S. 279 (1987). 
ing whites were more likely to receive the death penalty than white defendants charged with killing blacks. ${ }^{20}$ While assuming that the regression study was "valid statistically," 21 the Court nonetheless concluded that "[a]t most, the . . . study indicates a discrepancy that appears to correlate with race."22

In contrast to the methodology used in the McClesky v. Kemp study, this paper presents a test for discrimination in bail setting based on the rates bond dealers charge after bail is set. Underlying our approach is the familiar economic concept of competitive pricing. In a competitive market, the bail bond rate (i.e., the bond fee divided by the bail amount) should approximate the market's assessment of the defendant's probability of flight-because the bond dealer's expected cost of writing a bond is simply the amount of the bond multiplied by the probability that the defendant will flee. ${ }^{23}$ For instance, if there is a 10 percent chance that a defendant will fail to appear, bond dealers in a competitive market should charge a 10 percent bond rate.

Our core finding is that bond dealers in New Haven charged significantly lower rates to minority defendants than to whites: For example, in our data, bond dealers charged black male defendants rates that were almost 19 percent lower than the rates charged to white male defendants. ${ }^{24}$ This race differential in the bond market, we argue, raises the specter of unjustified racial discrimination at the bail-setting stage. The lower minority rates indicate that bail reduced the probability of flight for minority males below the flight probability for white males. Our results showing significantly lower bond rates (alongside a traditional regression showing significantly higher bail amounts for black defendants in our sample) constitute powerful market evidence of unjustified racial discrimination in bail setting. The market evidence indicates that judges in setting bail demanded lower probabilities of flight from minority defendants. Judges could have reduced bail amounts for minority males without incurring flight risks higher than those deemed acceptable for white male defendants.

Moreover, our analysis avoids the problem of omitted variable bias. Bond rates provide a market-disciplined assessment of a defendant's probability of flight, given her bail amount. As a result, bond rates obviate the need to observe and measure defendant characteristics which, in traditional discrimination studies, serve as indirect proxies for the defendant's flight probability. ${ }^{25}$ Knowledge about bond prices substitutes for the traditional requirement that the researcher control for everything that might have affected courts' decisions. Specifically, evidence that bond dealers charge blacks lower rates makes it im-

20. The study in question was David C. Baldus, Charles Pulaski \& George Woodworth, Comparative Review of Death Sentences: An Empirical Study of the Georgia Experience, 74 J. CRIM. L. \& Criminology 661 (1983).

21. 481 U.S. at 291 n.7.

22. Id. at 312 (emphasis added). The district court specifically criticized the study's treatment of unknown variables. McCleskey v. Zant, 580 F. Supp. 338, 357-59 (N.D. Ga. 1984).

23. Possible exceptions to this proposition are addressed in notes 110-128 infra and accompanying text.

24. See note 96 infra and accompanying text.

25. Our market test assumes that bond dealers have the same information as the bail setter. We explore the possibility that bond dealers have access to additional information in our discussion of sample selection at notes 161-165 infra and accompanying text. 
plausible to contend that the black defendants in our sample had a higher propensity to flee and therefore needed higher bail amounts to induce a sufficiently low probability of flight. Put simply, evidence of lower market bond rates for blacks suggests that courts could set lower bail for black defendants without incurring abnormally high risks of flight.

In this article, we emphasize that the racial disparity in bail amounts and bail bond rates might be explained by a number of alternative, nondiscriminatory rationales. ${ }^{26}$ But the presence of market information, at the very least, shifts the grounds of debate. In the face of this evidence, one cannot plausibly argue that our failure to control for certain variables induced the racial disparity, nor can one argue that this disparity serves the purpose of the law. ${ }^{27}$

Thus, while observers of the criminal justice system have traditionally regarded bond dealers with scorn, their pricing behavior, when disciplined by competition, is useful in evaluating government bail setting procedures. Moreover, our study suggests that bond dealers in competitive markets may provide an additional service of mitigating the effects of state discrimination. Although bail amounts for black male defendants average 35 percent higher than for white male defendants, the bond fees that black males pay are only 16.5 percent higher. ${ }^{28}$ For all its faults, this pariah industry may be responsible for mitigating more than half of the effects of racially disparate bail setting. ${ }^{29}$

This article has four parts. Part I describes the bail bonding system in Connecticut and provides a theory for the actions of courts, bond dealers, and defendants. Part II describes our empirical results. We find evidence that: (1) the bail bond market in New Haven, Connecticut, is reasonably competitive; (2) bail amounts for black and Hispanic male defendants are significantly higher than for white male defendants; and (3) bail bond rates for black and Hispanic male defendants are significantly lower than for their white counterparts. We argue that if three crucial assumptions are valid, the market test of discrimination provides evidence that bail setting has an unjustified disparate impact on minority males. Part III explores several ways that each of these three assumptions might fail and provides alternative, nondiscriminatory explanations for

26. In Part III of this article, we explore three types of nondiscriminatory explanations. See notes 109-165 infra and accompanying text.

27. The lower bond rates are inconsistent with a statistical discrimination explanation because competition should force bond dealers to rely on the same racial inferences that any court might use. Even after making statistical inferences about race, however, bond dealers consistently offer lower rates to blacks. This indicates that judges demand a higher certainty of appearance from black defendants than from whites.

28. See text accompanying note 100 infra.

29. The results for Hispanic males are even more dramatic. While bail levels for Hispanic males are $19.4 \%$ higher than for white male defendants, their bond dealer fees are only $4.6 \%$ higher. See text accompanying note 100 infra.

As discussed below, perfect competition among bond dealers need not necessarily eliminate all effects of discrimination. See text accompanying notes 101-103 infra. For example, if raising bail amounts by $10 \%$ only reduced the probability of flight by $3 \%$, then minority defendants would still expect to pay higher fees because competition would eliminate only $30 \%$ of any judicial discrimination. It is also possible that bond dealers themselves discriminate against minorities. This would suggest that but for bond dealers' discrimination even more of the judicial discrimination would be eliminated by bond dealer competition. 
our results. Part IV argues that, while market competition may help to mitigate unjustified judicial bias, complete reliance on remedial market correction places too much confidence in the resilience of competitive forces, given the evidence currently available. In the concluding section, we suggest some of the broader implications of our findings and methodology, along with possible applications to other market settings.

\section{A Theory of Bond Dealers, Defendants, and Court Behavior}

An empirical study is only as good as the structural theory underlying it. Thus, we first examine the institutional features of the Connecticut bail system, and then construct a theory of strategic interaction between the defendant, the court, and the bond dealer.

\section{A. Institutional Features of Connecticut Bail Setting}

In Connecticut, defendants have opportunities to gain pretrial release at several stages after arrest. When police arrest a defendant, they must either release her on a written promise to appear (PTA) or set a money bail amount. If they set monetary bail, the defendant may then arrange terms with a bail bond dealer. If a defendant does not arrange for immediate release, a bail commissioner reviews her bail and has discretion to change (usually lower) the bail amount set by the police. At this point, the defendant may once again attempt to arrange terms with a bail bond dealer. If the defendant is still unable to secure release, a judge reviews (and may lower) her bail. ${ }^{30}$ Once again, the defendant can arrange terms with a bail bond dealer. ${ }^{31}$

In 1990, the year for which we analyzed New Haven bail data, 217,539 individuals were arrested in Connecticut (30 percent of whom were black). ${ }^{32}$

30. Judicial review must normally occur within 48 hours of arrest. See County of Riverside v. McLaughlin, 500 U.S. 44 (1991) (holding that jurisdictions combining probable cause determinations with other pretrial proceedings must make these determinations within 48 hours of arrest).

31. This multistage process could be modeled as a series of three offers to sell pretrial freedom. Such a model is particularly apt because the state's offers almost inevitably decline at each subsequent stage, as is common in bilateral bargaining. In future work, we will attempt to derive the state's optimal concession curve given a variety of objectives. We hope to use our estimates of the actual concession curve of the state to assess what objective function best describes the state's bail setting practices.

This suggests another nondiscriminatory explanation for the higher bail amounts set for black defendants: Black suspects may more readily accept earlier (and higher) offers made by the police or the bond commissioner. Under this explanation, the state may offer similar concessions to all suspects-but black suspects may simply be more likely to accept the higher early offers. This selection effect would violate the statutory mandate that bail be set at the lowest level that reasonably assures appearance. The state's concession strategy - which produces lower bail for those defendants who wait-could only be justified if impatient suspects (those more likely to accept the first offer) are also more likely to flee. However, if the acceptance of higher initial offers is what produces the higher bail figures for blacks, then we should not find that blacks receive lower bond rates, since bond dealers presumably would also be aware that these impatient defendants pose higher flight risks. In addition, a uniform concession strategy that adversely affects minorities might raise disparate impact concerns similar to those that frequently arise in employment cases.

32. Division of State Police, Connecticut Department of Public Safety, Connecticut Uniform Crime Reporting Program-1990, at 33 [hereinafter Uniform Crime Reporting ProGRAM] (reporting that 66,350 out of 217,539 arrestees were black). These state data do not distinguish between Hispanic and non-Hispanic whites. 
Sixty-five percent of those arrested were released on promises to appear or accepted the bail amount set by the police and were released before being interviewed by a bail commissioner. ${ }^{33}$ Of those defendants appearing before bail commissioners prior to arraignment, 7.5 percent made bail using the services of a bond dealer, and another 33 percent secured release on either a nonsurety bond or a PTA. ${ }^{34}$ Of those defendants still in detention at arraignment, 16 percent had their cases disposed, 37 percent made bail using a bond dealer, and 40 percent secured release on either a nonsurety bond or a PTA. ${ }^{35}$

During that same year in New Haven alone, police arrested 8540 individuals (55 percent black, 32.4 percent Hispanic, and 12.6 percent white). ${ }^{36}$ While our data for New Haven do not identify when defendants were released, they do identify the conditions of release. Of those arrested, 83.5 percent secured release on a PTA, and 0.6 percent secured release on a nearly equivalent nonsurety bond; ${ }^{37} 1.8$ percent posted bail themselves, 10.9 percent posted bail using the services of bond dealers, and 3.2 percent remained in jail. ${ }^{38}$

The bonds studied below were written by "professional" bond dealers. ${ }^{39}$ In essence, these bond dealers sell the state "flight insurance." If they agree to write a bond for a defendant-or to "take him out" in industry parlance-they promise to pay the state the bail amount in the event the defendant fails to

33. Id:; Superior Court Barl Commission, State of Connecticut Judicial Department, An. NUAl Report, at tbl. A (1990) [hereinafter Commission Report] (reporting that 74,675 arrestees, or $35 \%$ of the total number of arrestees $(217,539)$ were interviewed by a bail commissioner during 1990 ). Although this article focuses solely on discrimination in setting bail, discrimination could also affect the probability of being released on a promise to appear (PTA). For example, while $75.1 \%$ of white (including Hispanic) defendants were released before a bail commissioner interview, only $44.7 \%$ of black defendants were released at this early stage. See Uniform CRIME Reporting Program, supra note 32, at 33 (reporting a total of 150,519 white and 66,350 black arrestees during 1990); CoMmission REPORT, supra, at tbl. B (26,827 white arrestees, or $24.9 \%$ of total, were interviewed by bail commissioner, while 30,655 black arrestees, or $55.3 \%$ of total, received such interviews). Our interviews with the bail commission suggest that many of these early releases were costless PTAs.

34. Commission Report, supra note 33 , at tbl. A (16,441 of the 49,561 persons interviewed by bail commissioners were released on PTAs or nonsurety bonds; 3,715 used bond dealers). With a nonsurety bond, a defendant need not post any assets as a condition of release, but incurs a monetary penalty if he or she fails to appear. A PTA release is similar but imposes no monetary penalty at all. In either case, however, a defendant who chooses to flee may incur new criminal liability for the independent crime of failing to appear.

35. Id.

36. State of Connecticut, Judicial Branch, Criminal/Motor Vehicle Statute File (1991) (computer tape, on file with author) [hereinafter Connecticut Justice Department Tape].

37. Id. Surprisingly, the state apparently does not prefer using nonsurety bonds even though the state can garner higher forfeitures from such bonds. Officials suggested that, for many defendants who were judgment proof, nonsurety and PTA releases were often monetarily equivalent.

This 1990 data resembles Malcolm Feeley's 1973 analysis of the same New Haven court: He found that $52 \%$ of defendants were released on a PTA, $37 \%$ were released on bail, and $11 \%$ were detained until trial. FeELEY, supra note 14, at 202. However, the trend has been for defendants to post their own bail less frequently and for the percentage of PTA releases to increase.

38. Connecticut Justice Department Tape, supra note 36.

39. There are two types of bond dealers in Connecticut. Professional bond dealers are licensed and regulated by the Commissioner of State Police. Insurance bond dealers are licensed as insurance agents by the state Insurance Commissioner and write bond contracts for insurance companies specializing in this type of surety bond. Paul Rice, Bail and the Administration of Bail in the State of Connecticut, 4 CONN. L. REv. 1, 26 (1971). The state permits insurance bond dealers to charge somewhat higher rates than professional bond dealers. Id. at 26-28. 
appear in court. ${ }^{40}$ Bond dealers incur no up front capital costs on bonds. They do not post any money in advance, and while the total amount of bonds a given bond dealer may have at risk must not exceed a bond dealer's total capital, this capital can remain invested in interest-bearing assets. ${ }^{41}$

Bond dealers may refuse to write bonds for particular defendants. Should they choose to accept a defendant's business, however, the fees they charge are subject to regulation. For bail amounts up to $\$ 5000$, a professional bond dealer may charge fees of no more than 10 percent of the bail amount. For bail amounts in excess of $\$ 5000$, a bond dealer may charge up to 10 percent for the first $\$ 5000$ and up to 7 percent of the portion which exceeds $\$ 5000 .{ }^{42}$

In the next two sections we present a theory of how bond dealers and state officials interact to determine a defendant's pretrial release status. We first analyze how, given the bail amount for a particular defendant, a bond dealer would set fees in a competitive market. We then examine how a court (or other bail setter) would choose the minimum bail amount that will "reasonably assure" the defendant's appearance.

\section{B. Determinants of Bond Dealers' Fees in a Competitive Market}

Competition among bond dealers in New Haven is critical to our analysis. Competitive theory suggests that the rates charged by bond dealers ${ }^{43}$ should reflect defendants' flight risk. In what follows, we present evidence that the rates charged by bond dealers are inversely related to the number of dealers competing in a city. In cities with little competition, bond dealers simply charge the maximum statutory rate. In cities like New Haven, where there are several bond dealers, the bail bonding rate is well below the statutory maximum, suggesting that competition depresses rates to reflect bond dealers' true costs. ${ }^{44}$

40. Bond dealers forfeit approximately $50 \%$ of a bond's face value when a defendant fails to appear. See note 118 infra and accompanying text. The $50 \%$ forfeiture rate effectively increases the maximum rate that bond dealers may legally charge. Even though bond dealers, by statute, cannot charge more than a $10 \%$ fee on a $\$ 5000$ bail, see note 42 infra, the $50 \%$ forfeiture rate allows bond dealers to charge a $\$ 500$ fee when they only have $\$ 2500$ at risk.

Because the $50 \%$ forfeiture rate does not apply to defendants who personally post bail, this forfeiture rate is a great inducement to use professional bond dealers. A defendant with a $\$ 5000$ bail may either risk that entire $\$ 5000$ or pay a bond dealer to risk a mere $\$ 2500$. At text accompanying notes 117118 infra, we explore the impact of the 50\% forfeiture rate on our discrimination tests. Given the $50 \%$ forfeiture rate and the uncorrelated nature of bond risks, it is puzzling that the value of professional bond dealers' total outstanding bonds may not exceed their capital. A $100 \%$ reserve ratio is much higher than the rate required for commercial banks.

41. See Conn. Gen. Stat. Ann. §§ 29-145 to -146 (West. Supp. 1993).

42. Id. $\$ 29-151$ mandates that no professional bond dealer:

shall charge for his commission or fee more than fifty dollars for [any amount of bail] up to five hundred dollars, nor more than ten percent of the amount of bail ... from five hundred dollars to five thousand dollars, nor more than seven percent of the amount of bail . .. in excess of five thousand dollars.

43. Recall that the bond rate is the ratio of the bond dealer's fee to the bail amount. See text accompanying note 23 supra.

44. See text accompanying notes $75-76$ infra. 
Our market test of discrimination assumes that competition in New Haven drives the bail bonding fees to equal the bond dealers' expected costs, and that the bond rates will consequently be proportional to flight risks for each defendant. Absent competition, bond dealers may charge what they believe the market will bear-discriminating based on the defendant's willingness to pay. Competition may eliminate price discrimination, because a competitor has an incentive to undercut any discriminatory price charged by competitors that is above expected cost. ${ }^{45}$

In Appendix A, we derive a technical model of competitive fee setting. ${ }^{46}$ We present a simplified version here, to illuminate the intuition that in a competitive market, bond dealers' rates are likely to be proportional to the probability that a defendant will flee.

Our model uses the following notation:

$B=$ bail amount set by the state,

$f=$ forfeiture rate (fraction of $B$ forfeited if the defendant fails to appear), ${ }^{47}$

$p=$ probability of flight, ${ }^{48}$

$R=$ total nonrefundable fee paid to the bond dealer,

$r=R / B$ (bond rate the defendant pays to the bond dealer), and

$C=$ value of the defendant's available collateral. ${ }^{49}$

The bond dealer's expected profit on any individual bail bond equals the fee paid, less the money forfeited when a defendant fails to appear discounted by the probability of such an occurance, ${ }^{50}$ plus any proceeds the dealer derives from sale of bond collateral..$^{51}$ The expression for profit $(\Pi)$ is thus:

45. For elaboration of this argument in the employment context, see GARY S. BECKER, ThE ECoNOMICS OF DisCRIMINATION (1957).

46. See text accompanying notes 181-183 infra.

47. The forfeiture rate in New Haven during this period was approximately $50 \%$. See note 118 infra and accompanying text.

48. The bond dealer's payoff turns on whether a suspect flees and avoids recapture for six months. One can interpret " $p$ " as the probability of flight minus the probability of recapture. In the more complicated model presented in Appendix A, we explicitly include the costs of search and probability of recapture to reflect the fact that bond dealers are more likely to try to recapture suspects as the bail amount increases. See text accompanying notes 181-183 infra.

49. Collateral serves two distinct purposes: (1) it deters flight, and (2) it compensates bond dealers if suspects flee. The value of the collateral to the suspect determines its value as a flight deterrent, while its value to the bond dealers usually determines its usefulness as compensation. Bond dealers might accept collateral with little market value if it has significant personal value to the suspect-and hence would deter the suspect from flight. See Oliver E. Williamson, Credible Commitments: Using Hostages to Support Exchange, 73 Am. Econ. Rev. 519 (1983).

50. Note that interest costs are zero because bond dealers do not actually post bond; rather, they promise to pay should their customer fail to appear. In the interim, bond dealers continue to earn interest on their invested capital. See text accompanying notes 40-41 supra.

51. A more complete bond dealer model might:

(1) Include the bond dealer's fixed administrative costs of doing business. Below, we estimate the size of fixed costs and their impact on our results. See notes 123-128 infra and accompanying text.

(2) Allow for differences between the market value and the defendant's personal valuation of collateral. If personal and market values differ, $p$ would be a negative function of the defendant's personal 


$$
\Pi=R-p(f B+C) \text {. }
$$

Under the traditional assumption that competition drives profits toward zero, we can derive the market rate for a bail bond $(r)$ by setting the above profit expression equal to zero and solving for $r$. This calculation yields: ${ }^{52}$

$$
r=p(f-C / B) \text {. }
$$

The collateral term $(C / B)$ in the expression above poses a problem for our theory because it indicates that defendants with higher bail amounts $(B)$ could face higher rates $(r)$ even though they do not pose greater flight risks. ${ }^{53}$ If we make the plausible assumption that the value of the collateral required by bond dealers is proportional to the bond amount $(C=\alpha B)$, it is possible to preserve the proportionality of bond rates and flight risk. ${ }^{54}$ Substituting this value for $C$ in the rate equation, yields:

$$
r=p(f-\alpha) \text {. }
$$

Because the term $(f-\alpha)$ is a constant and does not depend on the bail amount, the bond rate remains proportional to the probability of flight. ${ }^{55}$

valuation, while $C$ would equal the market value of the collateral. We discuss the empirical importance of collateral below. See notes 119-122 infra and accompanying text.

(3) Include the costs of ex ante monitoring and ex post search. We include these costs in the model derived in the Appendix. See text accompanying notes 181-183 infra.

52. Setting the profit expression equal to zero yields:

$R-p f B+p C=0$.

Dividing this equation by $B$ (and remembering that $r=R / B$ ) yields:

$r-p f+p C / B=0$.

Solving for $r$ yields the expression in the text.

53. For example, consider two defendants who post $\$ 200$ in collateral. Assume that the first defendant has a higher flight propensity and therefore needs a higher bail amount to deter flight. By setting bail at $\$ 2000$ for the first defendant and at $\$ 1000$ for the second defendant, the judge can ensure that each has only a $10 \%$ chance of flight. Finally, assuming a forfeiture ratio of $50 \%$, the first defendant will be charged a bond rate of:

$$
r=p(f-C / B)=.1(.5-.1)=.04
$$

while the second defendant will be charged a bond rate of:

$$
r=.1(.5-.2)=.03 \text {. }
$$

Although the judge has succeeded in equalizing the flight probabilities of the two defendants, the first defendant is forced to pay a higher rate. This is because, compared to his bail amount, his collateral is relatively smaller.

Later, we present empirical evidence that collateral does not affect the pricing of bail bonds. See text accompanying notes 119-122 infra. For our proportionality assumption to hold, however, we need not assume that dealers' proceeds from disposing of collateral are zero.

54. The possibility that collateral does not bear a constant relationship to the bail amount-so that $\alpha$ differs across demographic groups-does not necessarily invalidate our test for race discrimination. Because African-Americans are, on average, poorer than whites, one might conjecture that black defendants would post less coilateral. This would suggest that bond rates for blacks should be higher, on average, than for whites. This would make our finding that bond dealers charge blacks lower rates even stronger evidence of discrimination.

55. If the defendant does not offer the bond dealer any collateral, this expression simplifies even further:

$$
r=p f .
$$


FIGURE 1

Flight Schedule: Higher Bail Amounts Reduce the Probability of Flight, Allowing Judges to Achieve Any Desired Probability of Flight

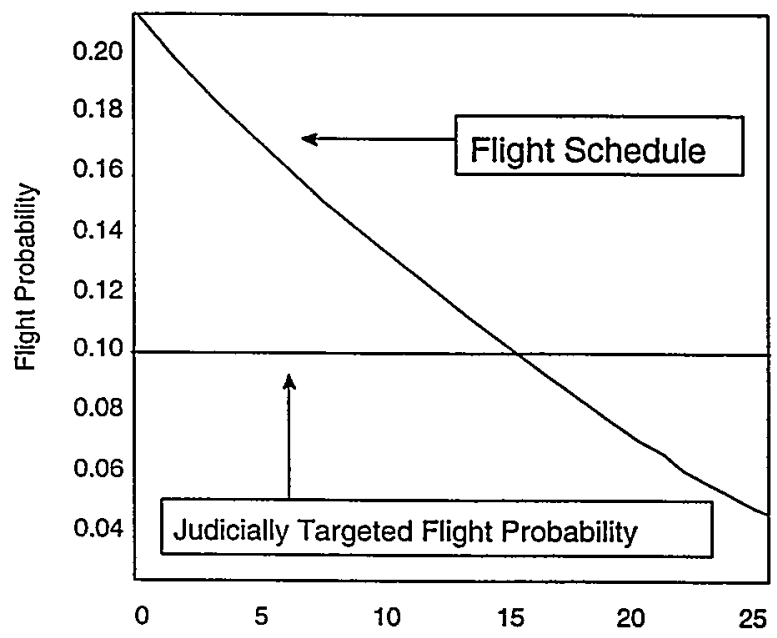

Bail Amount (000s)

To reiterate, our market test of discrimination relies on the assumption that the bond rate is proportional to the probability of flight regardless of the size of bail. Even if strict proportionality does not hold, ${ }^{56}$ the intuition remains that defendants with higher probabilities of flight will be charged higher bond rates to compensate the dealer for the greater risk.

As argued in the introduction, ${ }^{57}$ higher bail amounts might deter flight even in the presence of bond dealers because defendants know that higher bail encourages enhanced monitoring and search efforts by bond dealers. Figure 1 illustrates the notion that probability of flight decreases if the bail is set higher for any particular defendant. ${ }^{58}$

The downward sloping curve in Figure 1 represents a hypothetical defendant's flight schedule (the relationship between bail amount and probability of flight). It also is proportional to the bond dealer's rate schedule for a hypothetical class of defendants who differ only by their bail amount. Because competition causes the bond dealer's rate to be proportional to the defendant's flight probability, dealers serving defendants who differ only by the amount of bail will tend to charge lower rates to those with higher bail.

In this case, the bond rate is simply a market estimate of the defendant's probability of flight, multiplied by the forfeiture rate.

56. For reasons why strict proportionality may not hold, see notes 110-128, 182-183 infra and accompanying text.

57. See text accompanying notes 6-10 supra.

58. William Landes' pathbreaking study of bail setting found this inverse relationship. See Landes, supra note 5, at 322 . Other scholars have argued, however, that higher bail does not reduce the probability of flight. See Clarke et al., supra note 9, at 376. 
FIGURE 2

Different Propensities of Flight Can Shift the Flight Schedule

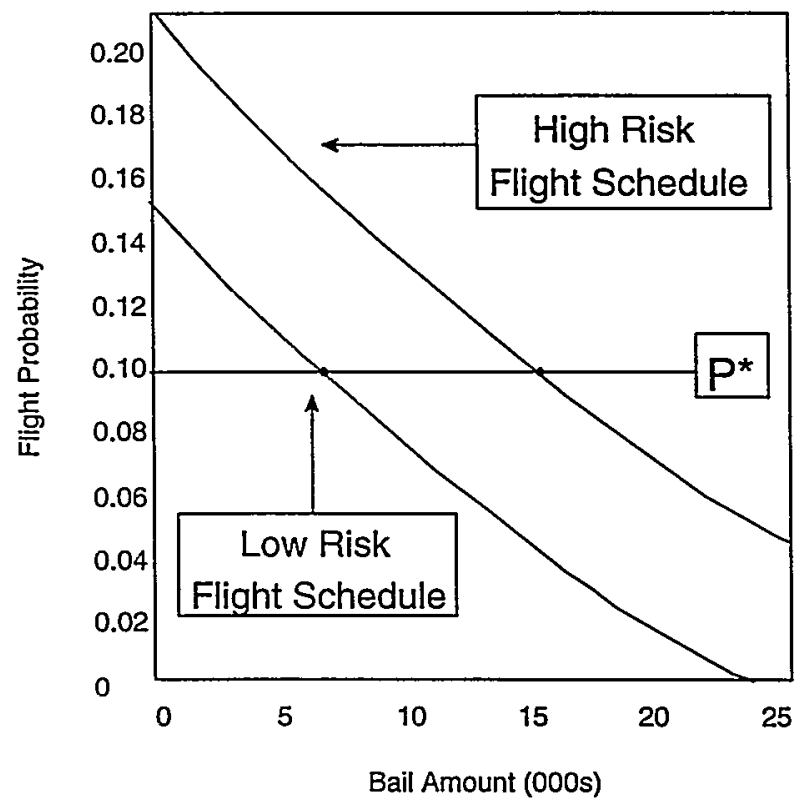

\section{Determinants of Bail Amount}

Given the flight schedule hypothesized above, our next step is to analyze how bail is set. Our analysis of the bail setting process relies on a second assumption which we call the "equalization" assumption. The equalization assumption states that the only legitimate purpose of bail is to reduce the probability of flight to a uniformly low level for all defendants. Such a rationale excludes other purposes, even if nondiscriminatory (e.g., punishment, incapacitation, retribution, etc.). While we discuss these possible alternate rationales in a subsequent section, ${ }^{59}$ Connecticut law supports the assumption that flight risk equalization is the sole permissible use of bail.

Until recently, Connecticut General Statute § 54-64a required courts setting bail to choose the minimum bail amount that would "reasonably assure the appearance of the arrested person in court." 60 A reasonable interpretation of

59. See notes 129-155 infra and accompanying text.

60. Conn. Gen. Stat. AnN. \$ 54-64a(a)(1) (West 1985). The statute and accompanying court rules explicitly detail the factors that courts may consider in setting bail.

On October 1, 1990, amendments to $\$ 54-64 a$ took effect which mandated that courts set bail for certain felonies "sufficient to reasonably assure . . . that the safety of any other person will not be endangered." Conn. Gen. Star. Ann. \$ 54-64a(b)(1) (West Supp. 1993). Bail set after this date may reflect this additional criterion. Limiting our data to the period before October 1, 1990, however, did not affect our results. Our discussions with Connecticut bail commissioners indicate that judges rarely used this "safety of any other person" criterion. This may be because the amended statute arguably permits use of this criterion only when judges determine that the released defendant may commit another crime "based upon the expressed intention of the" defendant. Id. $\$ 54-64 \mathrm{a}(\mathrm{b})(2)(\mathrm{L})$. Moreover, even if judges had begun inflating bail amounts based on the "safety" criterion, the purpose would have been to set bail 
the statute is that courts should set bail for each defendant so as to reduce his or her flight probability to some acceptably low uniform level. For example, the statutory mandate could mean that judges should set bail high enough to ensure that there is no more than a 10 percent chance that any defendant will flee. Figure 1 depicts this goal as a horizontal line intercepting the "Flight Probability" axis at $p=0.10$. To set bail in accordance with the statute's mandate, a judge would thus select a bail amount represented by the intersection of the flight schedule with the horizontal line representing the targeted flight probability. In Figure 1 this intersection occurs at approximately $\$ 15,000$.

Different defendants will often have different flight propensities, however. For instance, defendants facing serious charges or those who have weak community ties might be less likely to appear. ${ }^{61}$ Judges may therefore have to vary the amount of bail to produce a uniform probability of appearance for defendants with unequal propensities to flee. ${ }^{62}$ To see this, suppose that (as depicted in Figure 2) two defendants have differing flight propensities for every bail amount. To induce a uniform 90 percent probability of appearance, the Court must set bail for the high-risk defendant at $\$ 15,000$ and for the low-risk defendant at only $\$ 6000$.

Thus, the empirical observation that courts set widely varying bail amounts for different defendants is consistent with the judicial goal of equalizing flight probability. As Landes notes, "one might observe identical probabilities of disappearance across defendants with different size bonds." 63

Before proceeding with the empirical analysis, we must take note of three caveats to our equalization assumption. First, while we interpret the Connecticut statute to require a uniform probability of appearance for all defendants, we recognize that bail setters may in fact consider a variety of other nondiscriminatory criteria (both consistent and inconsistent with the statute). We directly address a number of these alternative criteria and their impact on tests of discrimination in a later section. ${ }^{64}$

The second caveat is that we have interpreted the statute to mandate equalizing the probability of appearance conditioned upon the defendant's release from jail. This is an important qualification because conditional and unconditional probabilities of appearance may diverge significantly. Our interpretation requires the judge to ask, "If this defendant makes bail, what bail amount would produce a 90 percent likelihood that she will appear in court?" An alternative interpretation (which we reject) focuses on unconditional probabilities of

high enough to force defendants to remain incarcerated pending trial, so it is not surprising that any such defendants would not have appeared in our data set (which only includes defendants released on bail bonds). For a judicial gloss on these amendments, see State v. Ayala, 222 Conn. 331, 342-54, 610 A.2d 1162 , 1169-74 (1992). flee).

61. See Myers, supra note 5 (analyzing factors that may influence a defendant's propensity to

62. By varying the bail amount, the judge can influence the effort that the bond dealer will expend on (1) monitoring a defendant's whereabouts before a scheduled appearance and (2) searching for a defendant who has failed to appear. See text accompanying note 8 supra.

63. See Landes, supra note 5 , at 321 n.46.

64. See notes 129-155 infra and accompanying text. 
appearance and requires judges to ask, "What bail amount will ensure a 90 percent appearance rate by deterring flight (if the defendant makes bail) or by precluding flight (if the defendant remains in jail)?" The language of the statute supports the conditional interpretation in that it emphasizes "conditions of release" necessary to assure appearance. 65 By implication, the statute does not contemplate incarceration as a method of assuring appearance. Moreover, an unconditional probability criterion can lead to anomalous results. For instance, even if a judge following an unconditional probability criterion is certain that a particular defendant will skip bail, the judge would be compelled to set bail sufficiently low to allow a 10 percent chance that the defendant will be able to make bail.

The third caveat concerns the interplay between judges and bond dealers. Under our equalization assumption, when judges set bail to equalize the probability of flight, they should ignore how dealers set their fees. One might expect that judges might attempt to predict the size of bond dealers' fees, and adjust bail to compensate for the workings of the bail bond market. Such behavior would, however, violate their statutory mandate to do no more than induce a reasonable assurance of appearance. ${ }^{66}$ Because the bond dealer's fee is a nonrefundable "sunk cost" to the defendant, ${ }^{67}$ it should not influence the defendant's probability of flight, and thus is not a factor judges should consider. ${ }^{68}$

Subject to these qualifications, our analysis of bond rates allows us to test whether minority defendants in our sample deserved the higher bail amounts we observe because these defendants had a higher propensity to flee. If courts set bail levels solely to equalize flight probabilities, then the rates charged by bond dealers should be equal for all defendants. If bail was set too high for black defendants, then the average risk of flight would be lower for blacks than for whites, and thus our data would show that black defendants pay bond dealers lower rates.

65. See Conn. Gen. Stat. Ann. § 54-64a(a)(1) (West Supp. 1993).

66. See id. For a discussion of other factors that might cause a judge to consider the size of bond dealer's fee, see notes 150-155 infra and accompanying text.

67. A sunk cost is one which a person has previously incurred; because it cannot be recovered or changed, its magnitude should not affect future behavior. See Richard A. Posner, Economic ANalysis OF LAw 7 (4th ed. 1992).

68. A judge attempting to equalize flight probabilities across defendants would consider how bail size affects dealers' efforts to monitor and search (since these efforts do affect the probability of flight), but monitoring and search effects depend only on bail size and not on how bond dealers have previously decided to price their services.

An analogous "sunk cost" argument applies to the behavior of bond dealers: Because the bond fee is a "sunk revenue," it should not affect a rational bond dealer's propensity to monitor or search for the defendant. Only the prospective threat of forfeiting the bail amount would influence the bond dealer's incentives. Thus, while a judge attempting to equalize flight probabilities across defendants would consider how bail size affects dealers' incentives to monitor and search (since these efforts affect the probability of flight), the judge need not consider any effect of fee levels on monitoring and search incentives. 


\section{Testing the Theory}

\section{A. A Description of the Bailbonding Data}

We based this study on data concerning defendants who were arrested and processed in the Court of Common Pleas in New Haven, Connecticut, during 1990, and who secured release using the services of bond dealers. We derived the data from Connecticut State Police records on professional bond dealers, and Connecticut Justice Department court records. ${ }^{69}$

We linked bond data (using defendant names and arrest dates) with the more detailed court data. Each court record included the defendant's race and gender, as well as offense and judge identifiers. ${ }^{70}$ Table 1 summarizes the data for the 1366 felony defendants whose records we were able to match in this manner.

The average bail amount in the sample is $\$ 3466$, and the average bond fee is $\$ 177$. The average age of the defendants is twenty-seven years. Seventeen percent of the defendants are female, two thirds are black, and 12 percent are Hispanic. The most common offenses are drug offenses ( 24 percent), assault (20 percent), disorderly conduct (13 percent), and larceny (10 percent).

\section{B. Evidence of Market Competition}

The model we designed to examine the relationship between bond rates and flight probabilities hinges on the existence of competitive pressures in the bail bond market. Thus, before we can assume that bond rates reflect the expected costs of flight, we must first establish that bond dealers in New Haven behave competitively. By comparing market concentration and bond dealer rates in nine Connecticut towns, we find that towns with many bond dealers, such as New Haven, have average rates far below the statutory maximum. This suggests that competition is indeed driving down rates to reflect expected costs.

The market for bail bonds in New Haven shares some, but not all, of the features of a competitive market. On the one hand, the New Haven market has unrestricted entry. More than twenty bond dealers wrote at least one bond on defendants arrested in New Haven in 1990. The Herfindahl index of market concentration-a traditional measure of market competition-was 1674 in New Haven. This level of concentration is analogous to the concentration of a market with six equally sized competitors. ${ }^{71}$ On the other hand, the market

69. Connecticut Justice Department Tape, supra note 36. Connecticut requires professional bond dealers to submit monthly and annual reports to the state police. These records include defendant names and arrest dates, as well as the defendants' bail amounts and fees paid to the bond dealers.

In addition, we collected reports directly from professional bond dealers operating in New Haven and several other Connecticut towns. We used these reports solely to compare the average rates paid in different towns.

70. The offenses were classified as $\mathrm{A}, \mathrm{B}, \mathrm{C}, \mathrm{D}$, and $\mathrm{U}$ misdemeanors and felonies. Judges were identified by numeric codes.

71. For a discussion and application of the Herfindahl index, see Ian Ayres, A Private Revolution: Markovits and Markets, 64 CHI.-KENT L. REv. 861, 865-68 (1988). 
TABLE 1

Sample Characteristics $(N=1366)$

\begin{tabular}{|lrr|}
\hline & Mean & Std. Dev. \\
\hline Bail Amount (B) & 3466.23 & 6651.3 \\
Fee Paid & 177.37 & 237.02 \\
Age & 27.10 & 8.60 \\
\hline & Percent of & \\
& sample & \\
\hline White Male (WM) & 18.7 \\
White Female (WF) & 4.5 \\
Black Male (BM) & 53.3 \\
Black Female (BF) & 11.5 \\
Hispanic Male (HM) & 10.6 \\
Hispanic Female (HM) & 1.4 \\
\hline Kidnapping & 0.4 \\
Prostitution & 0.7 \\
Rape & 0.1 \\
Assault (ASLT) & 19.7 \\
Gun Offense & 7.1 \\
Disorderly Conduct (DISOR) & 12.9 \\
Fraud & 1.9 \\
Failure to Appear (FTA) & 7.4 \\
Forgery & 0.9 \\
Larceny (LARC) & 10.0 \\
Arson & 0.2 \\
Burglary & 2.1 \\
Drug & 23.6 \\
Robbery (ROB) & 0.8 \\
\hline Class A or B Fel. (CLASABF) & 3.8 \\
Class C or D Fel. (CLASCDF) & 32.3 \\
Class U Felony (CLASUF) & 41.1 \\
Class A or B Misd. (CLASABM) & \\
Class C or C Misd. (CLASCDM) & \\
\hline
\end{tabular}


may not be perfectly competitive because some defendants may be poorly informed or face significant costs in searching for competitive bids. ${ }^{72}$

Table 2 compares bond market data from nine Connecticut towns. For each town, the table lists the number of active bond dealers, ${ }^{73}$ the average bond rate paid, and bond fees as a percentage of the statutory maximum. ${ }^{74}$ Where data are available, the table also lists the percentage of persons below the poverty line in 1979, and per capita income in 1985.

Three towns, New Haven, Bridgeport, and Norwalk, have three or more active bond dealers. Bond rates in New Haven, with eight active bond dealers, average 64 percent of the statutory maximum. Bond rates in Bridgeport and Norwalk are similarly low, averaging 78 and 54 percent of the maximum, respectively. The remaining six towns, by contrast, have only one or two active bond dealers, and their rates average 98 percent or more of the allowable maxima. The higher rates in these towns comport with traditional antitrust and industrial organization theories, which predict that prices should drop with the number of viable competitors. ${ }^{75}$ At a minimum, Table 2 suggests that the New Haven bail bond market is more competitive than the monopoly and duopoly markets in nearby cities. ${ }^{76}$

An alternative explanation for the lower rates observed in New Haven and certain other cities might be that defendants in these cities are poorer, and that bond dealers price discriminate, charging what individual defendants can afford. However, a closer look at the data summarized in Table 2 casts doubt on this hypothesis: While rates vary systematically with the number of bond dealers, rates are apparently not correlated with average incomes. Norwalk, for example, has high per capita income and a relatively low poverty rate, suggesting that defendants there might have a higher ability to pay for bond services. Yet bond rates in Norwalk, which has three active bond dealers, average only 54 percent of the maximum. In New London, by contrast, where per cap-

72. Defendants' limited access to information about bond dealers is dramatized by the inaccurate, but widely repeated, adage that prisoners are limited to "one phone call." In fact, jails normally allow multiple calls, and a defendant's lawyer, relatives, and friends often help arrange bond services. Several other factors, however, may still impede competitive pricing. As a practical matter, multiple bond dealers may not be available at all hours of the night. Moreover, even markets with many sellers may not be perfectly competitive. One of the authors of this article, for instance, has analyzed new car sales in the Chicago area and found that a large degree of price discrimination can persist even in a market with a large number of sellers. See Ayres, supra note 15; Ayres \& Siegelman, supra note 15; cf. Severin Borenstein, Price Discrimination in Free-Entry Markets, 16 RAND J. Econ. 380 (1985) (examining brand preference as a possible explanation for the persistence of price discrimination in consumer markets with many sellers).

73. The number of active bond dealers was derived from local telephone book listings.

74. Because bond rate ceilings vary according to the size of the bond, the average maximum statutory rate for a particular town depends on the distribution of bail bond amounts in that town.

75. See, e.g., Jean Tirole, The Theory of Industrial Organization 220-21, 226-28 (1988) (providing a mathematical demonstration of this effect and citing further literature). The bond rates in Table 2 do not decline monotonically as the number of bond dealers increases: three bond dealers in Norwalk charged only 54\% of the statutory maximum, while the eight bond dealers in New Haven charged $64 \%$ of the maximum. It is possible that Norwalk's relative affluence is correlated with attributes of bail setting that might explain this result.

76. The data in Table 2 may also reflect higher average costs per bond for dealers in small geographic markets with high fixed costs. 
TABLE 2

Market Structure and Bond Dealers' Rates ${ }^{\mathrm{a}}$

\begin{tabular}{|c|c|c|c|c|c|}
\hline Town & $\begin{array}{c}\text { Number of } \\
\text { Active } \\
\text { Bond } \\
\text { dealers }^{b}\end{array}$ & $\begin{array}{l}\text { Average } \\
\text { Rate } \\
\text { Paid }^{\mathrm{c}}\end{array}$ & $\begin{array}{c}\text { Percent of } \\
\text { Max. Rate } \\
\text { Paid }\end{array}$ & $\begin{array}{l}\text { Poverty } \\
\text { Rate }^{\mathbf{d}}\end{array}$ & $\begin{array}{c}\text { Per } \\
\text { Capita } \\
\text { Income }\end{array}$ \\
\hline New Haven & 8 & 4.1 & 64 & 23.2 & 9,378 \\
\hline Bridgeport & 10 & 7.3 & 78 & 20.4 & 9,427 \\
\hline Norwalk & 3 & 4.8 & 54 & 7.0 & 15,907 \\
\hline Meriden & 2 & 9.1 & 98 & 7.4 & 11,952 \\
\hline Ansonia & 2 & 7.9 & 99.6 & & \\
\hline Wallingford & 1 & 9.4 & 99 & & \\
\hline Stamford & 1 & 9.0 & 99 & 7.7 & 18,246 \\
\hline New London & 2 & 10.0 & 98 & 16.9 & 10,629 \\
\hline Plainville & 1 & 8.3 & 99 & & \\
\hline $\begin{array}{l}{ }^{\mathrm{a}} \text { Adapted from } \\
{ }^{b} \text { Derived from } \\
{ }^{c^{2}} \text { Ratio of the a } \\
\text { the state, in } \mathrm{p} \\
{ }^{d_{\text {Percent of pe }}} \\
\text { U.S. DEP'T O } \\
\text { 'Per capita inc }\end{array}$ & $\begin{array}{l}\text { Irkey, supra } \\
\text { low Pages lis } \\
\text { int paid to the } \\
\text { nt. } \\
\text { s below the p } \\
\text { MMERCE, Co } \\
\text { in } 1985 \text {, fror }\end{array}$ & $\begin{array}{l}\text { te 12, Appe } \\
\text { ggs. } \\
\text { ond dealer } \\
\text { erty line. } \\
\text { ITY AND CI } \\
\text { BUREAU OF }\end{array}$ & $\begin{array}{l}\text { lix I. } \\
\text { the bail am } \\
\text { REAU OF THE } \\
\text { DATA BOOK } \\
\text { HE CENSUS, }\end{array}$ & $\begin{array}{l}\text { nt set by } \\
\text { ENSUs, } \\
1988 \text {, at } 62 \\
\text { ra, at } 628 \text {. }\end{array}$ & \\
\hline
\end{tabular}

ita income is low, the two dealers charge an average of 98 percent of the statutory maximum. We conclude that the number of bond dealers per town, rather than the defendant's ability to pay, better explains the rate variation across towns. ${ }^{77}$

77. Anecdotal evidence from interviews we conducted with bond dealers in New Haven and Meridian, Connecticut, indicate that New Haven dealers undercut each other's rates more frequently than do dealers in other Connecticut towns, further supporting this conclusion. See also FreED \& WALD, supra note 3, at 24. ("Within the legal maximums . . . bondsmen frequently bargain for special rates, particularly in high volume, low risk offenses like gambling. Disputes between bondsmen over price cutting are not uncommon."); Forrest Dill, Discretion, Exchange and Social Control: Bail Bondsmen in Criminal Courts, 9 L. \& Soc'y Rev. 639, 647 (1975) ("Like many small businessmen, the bondsman operates in an environment offering neither steady demand for his services nor reliable means for guard- 
This evidence leads us to conclude that the New Haven bond market is relatively competitive, and that the lower rates charged in New Haven are not the result of price discrimination based on defendants' ability to pay. In a subsequent section, we consider whether bond dealers price discriminate on the basis of other factors, such as the defendant's information or search costs and whether the keener competition in New Haven is sufficient to drive bond prices all the way down to dealers' expected cost. ${ }^{78}$

\section{A Market Test for Discrimination in Bail Setting}

We derive our market test for discrimination in bail setting from a regression of the bond rate against offense and defendant characteristics, including the defendant's race and gender. The test simply asks whether minority defendants are charged bail rates that are significantly lower than those charged whites. If minorities and whites pay bond dealers the same rates, then interrace differences in bail amounts may be justified by unobserved factors correlated with both race and flight risk. On the other hand, if minorities face higher bail amounts but pay lower rates than whites, then the higher bail amounts for minority defendants must reflect racial disparity in bail setting.

This disparate rate test relies on three distinct assumptions, two of which we have discussed above. First, we assume that bond rates are proportional to expected flight probabilities. ${ }^{79}$ Second, we assume that bail setters impose bail amounts designed to equalize flight risks across defendants, and that flight probabilities decrease as bail increases. ${ }^{80}$ The final assumption, which we address more explicitly later, ${ }^{81}$ is that our data do not suffer from "sample selection" effects. In other words, we assume that the defendants who use bond dealers to post bail constitute a representative sample of all defendants. Given these three assumptions, our theoretical model predicts that rates should not vary systematically across defendants. If average bond rates for minorities are lower than average rates for whites, we can infer that bail set for minorities

ing against incursions by competitors. In other business settings such conditions foster highly competitive modes of behavior.").

If price discrimination based upon defendants' ability to pay were profitable, we would expect the greatest degree of price discrimination (and thus the greatest rate variance) to arise in towns with only one or two bond dealers, since bond dealers who face little or no competition are most likely to have sufficient market power to price discriminate. But the bond rates in towns with only one or two dealers are almost always at the statutory maximum. The example of New London is particularly strikingdespite the substantial poverty rate in the town, the dealer duopoly apparently engages in virtually no price discrimination.

78. See text accompanying notes 110-114 infra.

79. If our proportionality assumption fails, then we cannot infer that the judges failed to equalize the probability of appearance from our evidence of disparate rates. For a full discussion of this assumption, see notes 46-57 supra and accompanying text.

80. See notes 59-68 supra and accompanying text. If the bail amount did not affect the probability of flight, then judges could not use bail to equalize the probability of flight: Judges would set zero bail for those defendants who were reasonably likely to appear, and arbitrarily large bail for those who were not. Our empirical observation that judges set intermediate bails (that are consistently higher for minorities) would thus indicate a failure to follow the Connecticut bail statute's mandate to choose the minimum bail amount that is effective in deterring flight.

81. See text accompanying notes 156-165 infra. 
exceeds the level necessary to equalize the probability of flight across defendants.

While we base our market test for discrimination on bond rates alone, we jointly estimate both a bond rate equation and a bail equation for purposes of comparison and efficient estimation. We thus estimate the following equations using the "seemingly unrelated regressions" (or SUR) technique:82

$$
\begin{aligned}
& \ln B_{i}=\alpha_{b}+X_{i} \beta_{b}+\varepsilon_{i b} \\
& \ln r_{i}=\alpha_{r}+X_{i} \beta_{r}+\varepsilon_{i r}
\end{aligned}
$$

The regression equations above state that for each defendant $i$, the natural logs of both the bail amount $\left(B_{i}\right)$ and the bond rate $\left(r_{i}\right)$ are equal to a constant $\left(\alpha_{b}\right.$ and $\alpha_{r}$, respectively), plus a linear combination of defendant and offense characteristics $\left(X_{i} \beta_{b}\right.$ and $X_{i} \beta_{r}$, respectively) and an error or "noise" term ( $\varepsilon_{i b}$ and $\varepsilon_{\text {in }}$, respectively). ${ }^{83}$

The variables in the vector $X_{i}$ fall into three categories: defendant characteristics, offense severity, and offense category. Defendant characteristics include five race and gender dummy variables (for black women, black men, white women, Hispanic women, and Hispanic men), while white men form the benchmark (omitted) category. ${ }^{84}$ We divide offense severity into six categories and designate a dummy variable for each of the first five: class $A$ and $B$ felonies, class $C$ and $D$ felonies, class $U$ felonies, class $A$ and $B$ misdemeanors, and class $\mathrm{C}$ and $\mathrm{D}$ misdemeanors. Class $\mathrm{U}$ misdemeanors are the omitted category. Finally, we include dummy variables representing six offense categories: assault, failure to appear (FTA), larceny, drug-related offenses, gun offenses, and disorderly conduct. The omitted offense category includes the other offenses listed in Table $1 .{ }^{85}$

82. While a thorough review of econometric theory is beyond the scope of this article, a few concepts may be of use to the reader. The SUR technique is a way to estimate two different regression equations which, though "seemingly" unrelated to one another, are in fact related through their error terms. By estimating the equations jointly rather than separately, one can improve the precision of the estimates of the regression coefficients. For large data sets, the consequence of increased precision is a Iower variance of the estimator. Thus, it is possible that coefficients which appear statistically insignificant under standard techniques will test significant under the SUR technique. Indeed, the SUR technique is always more precise than the standard ordinary least squares (or "OLS") technique for large data sets. Hence, the SUR estimator is often referred to as an asymptotically efficient estimator. See, e.g., William E. Griffiths, R. Carter Hill \& George G. Judge, Learning and Practicing ECONOMETRICS 456-57, 550-55 (1993).

83. Note that for each defendant $i, X_{i b}$, and $X_{i r}$ are vectors of coefficients. This is a shorthand way of expressing rather lengthy linear functions.

84. A "dummy variable" resembles an on-off switch; it assumes a value of one if the defendant falls into a designated category, and zero if the defendant falls outside that category. By assigning dummy variables to all but one category, we can compare differences between any two categories. Thus, for a group of $\mathbf{n}$ mutually exclusive and exhaustive categories, we assign a dummy variable to (n-1) of these categories, and the regression provides us with the estimated coefficients for each variable. The estimated dummy coefficient represents the amount by which membership in the associated category increases or decreases the dependent variable (i.e., the bail or bond rate) as compared to the nondummy (or "omitted") category.

85. The data set includes 1118 observations which satisfy the following criteria: First, we include only those observations with judge identifiers. This allows us to use judge identifiers as instruments in later instrumental variables estimations. This restriction excludes about $5 \%$ of the sample. Second, we include only observations with positive rates paid to bond dealers. We include only these observations 
TABLE 3

Determinants of Bail and Rates Paid to Bond Dealers ${ }^{\mathrm{a}}$ (SUR Estimation)

\begin{tabular}{|c|c|c|c|c|c|c|}
\hline & \multicolumn{2}{|c|}{$\begin{array}{l}\text { Log Bail } \\
\text { Amount }\end{array}$} & \multicolumn{2}{|c|}{$\begin{array}{c}\text { Log Rate } \\
\text { Paid }\end{array}$} & \multicolumn{2}{|c|}{$\begin{array}{l}\text { Effect on Log } \\
\text { Fee Paid }\end{array}$} \\
\hline & coefficient & t-stat. & coefficient & t-stat. & estimate & t-stat \\
\hline CONST & $6.673^{* *}$ & 29.85 & -2.615 & $27.04^{* *}$ & & \\
\hline \multicolumn{7}{|c|}{ Defendant Characteristics } \\
\hline $\mathrm{BM}$ & $0.352^{* *}$ & 4.67 & $-0.188^{* *}$ & -5.76 & $0.165^{* *}$ & 2.58 \\
\hline $\mathrm{HM}$ & $0.194^{*}$ & 1.79 & $-0.148^{* *}$ & -3.16 & 0.046 & 0.50 \\
\hline WF & -0.057 & -0.38 & 0.030 & 0.47 & -0.026 & -0.21 \\
\hline $\mathrm{BF}$ & 0.075 & 0.71 & $-0.114^{* *}$ & -2.48 & -0.039 & -0.43 \\
\hline $\mathrm{HF}$ & -0.234 & -0.96 & -0.068 & -0.65 & -0.302 & -1.47 \\
\hline \multicolumn{7}{|c|}{ Offense Severity } \\
\hline CLASABF & $1.587^{* *}$ & 6.23 & $-0.186^{*}$ & -1.69 & $1.401^{* *}$ & 6.50 \\
\hline CLASCDF & $0.926^{* *}$ & 4.13 & -0.039 & -0.41 & $0.886^{* *}$ & 4.66 \\
\hline CLASUF & $0.683^{* *}$ & 3.43 & -0.069 & -0.80 & $0.615^{* *}$ & 3.64 \\
\hline CLASABM & -0.207 & -0.97 & $0.162^{*}$ & 1.75 & -0.045 & -0.25 \\
\hline CLASCDM & -0.300 & -1.28 & 0.146 & 1.44 & -0.154 & -0.78 \\
\hline \multicolumn{7}{|c|}{ Offense Category } \\
\hline ASLT & 0.052 & 0.67 & 0.045 & 1.14 & 0.107 & 1.38 \\
\hline FTA & -0.118 & -0.93 & 0.058 & 1.07 & -0.059 & -0.55 \\
\hline LARC & -0.043 & -0.37 & 0.083 & 1.64 & 0.040 & 0.41 \\
\hline DRUG & $0.519^{* *}$ & 4.03 & -0.035 & -0.62 & $0.485^{* *}$ & 4.44 \\
\hline GUN & $0.339^{* *}$ & 2.20 & 0.073 & 1.09 & $0.412^{* *}$ & 3.16 \\
\hline DISOR & $-0.367^{* *}$ & -3.50 & $0.115^{* *}$ & 2.54 & $-0.252^{* *}$ & -2.84 \\
\hline $\mathrm{R}^{2}$ & 0.387 & & 0.141 & & & \\
\hline $\mathrm{N}$ & 1118 & & 1118 & & & \\
\hline
\end{tabular}

The left hand columns of Table 3 report the bail regression results produced by equation (1). This regression constitutes the traditional test for discrimination. It suggests that race strongly influences bail levels. Specifically, average bail amounts for black and Hispanic men are 35 and 19 percent higher, respectively, than those for white men, and these differentials are statistically significant. ${ }^{86}$ White and Hispanic women appear to face lower bail amounts on

for two reasons: to avoid the results on rates paid bemg driven by nonpayment alone; and because it is more convenient to conduct the analysis in terms of logarithms. Neither our sample selection decisions nor the choice of logarithms affects the results reported below.

86. The differential between black and white defendants' bond rates is statistically significant from zero at the $99 \%$ significance level. The same is true of the differential between Hispanic and white rates at the $90 \%$ level. The race-gender coefficients approximate the percentage effect of belonging to a 
average than do white men, and black women appear to face bail amounts that are 7.5 percent higher than those faced by white men, but these differences are not statistically significant.

We find that crime severity has a large effect on bail. Bail amounts increase steadily with the severity of the offense, with Class A or B felony defendants (CLASSAB) facing average bail amounts 158 percent higher than those faced by Class $U$ misdemeanor defendants. ${ }^{87}$ Finally, we find that certain offense categories have a significant effect on bail size. In particular, bail for drug-related offenses averages 52 percent higher than bail for the benchmark category of offenses. ${ }^{88}$

By itself, this regression does not provide a very powerful test of race discrimination. Bail setters likely consider a number of factors that do not appear in our data set. In fact, the amended Connecticut bail statute explicitly allows courts to consider up to eight distinct factors when determining the bail level necessary to reasonably assure court appearance. ${ }^{89}$ The offense category variable included in the bail regression crudely controls for only one of these eight factors.

Without more, we cannot dismiss the possibility that the higher bail amounts for minority defendants reflect the courts' response to legitimate omitted factors. Courts may, for instance, set higher bail for unemployed defendants. If minority defendants are disproportionately unemployed, our inability to control for employment status will bias the race coefficient. ${ }^{90}$ Thus, while the bail regression indicates that bail setting has a disparate impact on minority males in our sample, the possibility of omitted variable bias prevents us from ruling out that this disparate impact is justified by observable factors affecting defendants' propensity to flee. ${ }^{91}$

given race-gender category. Interpreting regression coefficients as percentage effects is standard in studies of this kind. See, e.g., Jacob Mincer, On-the-Job Training: Costs, Retums, and Some Implications, 70 J. Pol. Econ. 50 (Supp. Oct. 1962).

87. For additional evidence that crime severity and defendants' prior records predict harm and thus affect bail amounts, see Landes, supra note 5, at 298-99.

88. The negative coefficient for the failure to appear offense indicates that the average bail amount set for defendants charged with failing to appear is lower than that set in the omitted offense categories. While this result is somewhat surprising because the prior failure to appear might itself be evidence of a higher propensity to flee, the result is not statistically significant. Moreover, some arrests in this category may only indicate a negligent failure to appear at a particular court date, rather than a genuine propensity to flee.

89. These factors include: (1) the nature and circumstances of the offense insofar as these are relevant to the risk of nonappearance; (2) the weight of the evidence against the defendant; (3) the defendant's record of previous convictions; (4) the defendant's past record of appearance in court after being released on bail; (5) the defendant's family ties; (6) the defendant's employment record; (7) the defendant's financial resources, character, and mental condition; and (8) the defendant's community ties. See Conn. Gen. Stat. Ann. \$§ 54-64a(a)(2), (b)(2) (West. Supp. 1993).

90. William Landes found that in New York, a defendant's employment and earnings have a significant impact on bail, although they are not related to the probability of appearance or the tendency to commit pretrial crimes. Landes, supra note 5 , at $326 \mathrm{n} .54$.

91. The $.387 \mathrm{R}^{2}$ coefficient itself suggests omitted variable bias, since it indicates that more than $60 \%$ of the variance in the amount of bail across defendants is not explained by variables included in the regression. This $\mathrm{R}^{2}$ does represent, however, the best goodness-of-fit found to date in a bail regression. For example, William Landes' regression model of bail setting explained only $23-27 \%$ of variation in bail amounts. Id. at 297 tbl.4. 
Using bail bond data potentially eliminates the need to control for the numerous other variables that might have influenced courts. Bond rate data make it possible to test for race discrimination in bail setting by running a simple regression of the bond rate (r) on the race dummy variables. A regression yielding statistically significant negative coefficients for the minority variables would constitute powerful evidence of discrimination in bail setting. This is true even if the regression excludes all other variables that might influence the riskiness of flight, and even if the regression "fits" the data poorly (i.e., produces a low $\mathrm{R}^{2}$ ratio). Unlike a traditional bail regression, omitted variable bias does not undermine the probative value of the rate regression for civil rights purposes.

The lower minority rates are still probative of the two elements necessary to establish a disparate impact claim. First, the coefficients indicate that judges set bail based on criteria that have a disparate impact on minority defendants. Second, these criteria are unjustified relative to the stated goal of limiting flight risk. ${ }^{92}$ The ability of this disparate rate test to overcome the problem of omitted variable bias makes it, at least in this respect, much more powerful than the traditional test of discrimination..$^{93}$ So long as our assumptions about proportionality, equalization, and sample selection hold, this disparate rate test establishes evidence of unjustified racial disparate impact even in the presence of omitted variable bias.

At a minimum, then, the bond rate test indicates whether judges use criteria that have disparate racial impact without the offsetting justification of equalizing flight risks. ${ }^{94}$ If the omitted variables do not bias the race coefficients, then the bond rate regression is probative of actual disparate racial treatment, not just of unjustified disparate impact. We reemphasize that these conclusions hinge on our earlier assumptions of proportionality, equalization, and absence of sample selection bias. In a later section, we explore several other nondiscriminatory explanations for the results that may pertain if these assumptions do not hold. 95

The center columns of Table 3 contain the coefficient and t-statistic estimates for the rate regression, which provide our prime evidence of racial discrimination. Most notably, after controlling for offense type and severity, black

92. In the employment context, the recently amended Title VII mandates that employers justify employment practices that have disparate impact by showing that they are "consistent with business necessity." 42 U.S.C. \$ 2000e-2(k) (1988 \& Supp. IV 1992).

93. The most extreme example of omitted variable bias would be to estimate the regression using only the race variables to explain the bond rate. This regression would be equivalent to estimating whether the means for different defendent race/gender types are statistically different. (They are.) While omitted variable bias would undermine any confidence that race caused the disparate rate, the finding that the average rate paid by minorities was significantly lower than the average white rate would be probative of some unjustified disparate impact.

94. Unjustified racial impact would be caused anytime a court raises bail based on factors that are not correlated with propensity of flight, but which are correlated with a defendant's race. For example, a judge might misestimate the impact of prior arrests on the defendant's flight probability and select a bail level which is higher than that necessary to obtain a "reasonable assurance of appearance." If these factors are disproportionately associated with minority defendants, then the minority coefficients in the bond rate regression could be negative and statistically significant.

95. See notes 109-165 infra and accompanying text. 
men, Hispanic men, and black women paid rates that are 18.8, 14.8, and 11.4 percent lower, respectively, than the rates paid by white men. ${ }^{96}$ Moreover, these differences are statistically significant. Because bond dealers are consistently willing to charge blacks and Hispanic men lower rates for putting their bonds at risk, we can reject the possibility that that black and Hispanic men pose higher flight risks justifying higher bail.

The coefficients for black female defendants also illustrate the limitations of the traditional bail regression test. Our bail regression indicates that bail set for black women is not significantly different from that set for white males. The traditional test therefore provides scant evidence of racial bias against black women. The bond rate regression, on the other hand, shows that bond dealers charged black women significantly lower rates (11.4 percent lower) than they charged white men. The statistical significance of the lower rate charged black women suggests that judges should have set lower bail for black female defendants in order to equalize flight risks. ${ }^{97}$

Table 3 indicates another striking phenomenon. The results show that variables with a positive effect on bail tend to have a negative effect on rates paid to bond dealers. For example, as the severity of the offense increases, the bail amount increases, but the rate paid by the defendant decreases. Defendants charged with drug related offenses (the offense with the highest average bail amount) pay bond dealers the lowest rates. This suggests that variance in bail is too high along dimensions other than race. ${ }^{98}$

\section{The Price of Pretrial Freedom}

While bail is the symbolic price of pretrial freedom, the actual price that most defendants must pay for pretrial release is the bond dealer's fee. This section uses data on bond dealers' fees to estimate the extent to which competition in the bail bonding market mitigates racial discrimination in bail setting.

The far right-hand column of Table 3 reports the effects of defendant characteristics on dealers' fees. The actual fee paid to the bond dealer is a product of the rate charged and the bail amount. ${ }^{99}$ Because dealers charge minority defendants lower rates when a judge has set excessive bail, the bail bond market can soften the impact of disparate bail setting on the price of pretrial freedom. Although bail levels for black and Hispanic men are 35.2 and 19.4

96. For instance, the bond rates for defendants charged with the misdemeanors falling within the omitted offense category were as follows: white males $7.32 \%$; black males $6.06 \%$; Hispanic males $6.31 \%$; white females $7.54 \%$; black females $6.53 \%$; and Hispanic females $6.84 \%$.

97. In fact, while bail amounts for black women were slightly higher than those for white men, these amounts were considerably higher than those for other women. The bond dealer data reveal no systematic discrimination against white and Hispanic women, as the rates charged to these two groups are not significantly different from the rates charged to white males.

98. One possibility is that courts wish to assure higher probabilities of appearance for more severe offenses. See notes 132-136 infra and accompanying text.

99. Because the regression equations (1) and (2) are estimated in natural logs, the percentage impact of a variable on the fee is the sum of the impact on log rate and the impact on log bail. For instance, the black male bond estimate (.165) is sum of the black male bail effect ( .352 from left-hand column) and the rate effect (-.188 from the center column). 
percent higher than for white men, the bond fees are only 16.5 and 4.6 percent higher, respectively. ${ }^{100}$ These statistics suggest that the bail bond market eliminates over half of the effect of the bail disparity for black men, and virtually all of the effect for Hispanic men.

Bond market competition cannot totally eliminate the impact of race discrimination, however, unless a 1 percent increase in bail results in a 1 percent decrease in the bond rate. Stated more generally, competition will fully mitigate the effect of discrimination only if the function relating bond rates to bail amounts displays what economists call "unitary elasticity."101 However, because we find that bond rates are actually fairly inelastic, ${ }^{102}$ we conclude that the bond market can only partially alleviate the impact of discriminatory bail setting. ${ }^{103}$

\section{E. Estimating the Extent of Discrimination in Bail Setting}

The disparate rate test indicates the presence, but not the extent, of race discrimination in bail setting. In order to estimate the extent of discrimination-the amount by which actual minority bail exceeds the bail necessary to achieve the maximum flight probability apparently targeted for white maleswe need to determine the relationship between bail amounts and flight probabilities for white and minority defendants. In essence, we need to determine the position of the defendants' flight schedules. Flight schedules are not directly observable, but we can estimate the position of the rate schedule, that is, the relationship between rates paid to bond dealers and bail amounts. If we continue to assume that the bond rates are proportional to the probability of flight, then knowing the relative position of the rate schedules for different race and gender types allows us to infer the relative positions of the corresponding flight schedules. In short, by estimating rate schedules we can test whether the minority defendants in our sample had higher propensities to flee and thus deserved somewhat higher bail amounts. We refer to this comparison of rate schedules as the "rate schedule test." Estimating the relationship between bail and the bond rate paid (i.e., the rate schedule) is difficult because the amount of bail is not independent of the flight risk. In Appendix B, we discuss how we

100. In fact, only black men pay a fee premium over white men that is statistically significant.

101. See note 189 infra for a discussion of the elasticity concept.

102. See Table 8 infra (estimating a bond rate elasticity of -.527 ).

103. In theory, it is easy to present pathological examples of flight probabilities that are extremely elastic with respect to the amount of bail. The degree of elasticity depends on the effectiveness of bond dealers' efforts to monitor and search, because these efforts determine the deterrence effect of additional bail. Suppose that a bond dealer has two methods of searching for a defendant who failed to appear. The first method costs $\$ 500$ and has a $10 \%$ chance of recapturing the defendant. The second method costs $\$ 10,000$ but has a $100 \%$ chance of recapture. If bail is set at $\$ 9000$, the bond dealer would be unwilling to use the second method, and, consequently, the bond dealer would charge a fee which reflects some possibility that the defendant will flee. However, if bail is set at $\$ 11,000$, the bond dealer will use the expensive search technology, and because of the $100 \%$ recapture rate, defendants will be strongly deterred from fleeing. If defendants are rational and respond to these probabilities to maximize their welfare, there would be a zero probability of flight, so the bond dealer would be able to charge a negligible fee since there is little risk. This kind of example could easily generate elastic flight schedules. It is implausible to suppose that flight schedules are elastic, however. If they were, defendants would clamor for higher bail amounts in order to reduce their fees. 
statistically control for the endogeneity of bail using an "instrumental variables" technique, and actually estimate rate schedules for different defendants. ${ }^{104}$

The rate schedules estimated in Appendix B indicate that race is not related to flight propensity. After accounting for bail, bond rates paid by minority men are not significantly different from rates paid by white men. ${ }^{105}$ The insignificance of the race dummies for men suggests that race is not related to the propensity of a defendant to flee: Minority men have roughly the same flight schedule as do white men.

Since white and minority males appear to have the same rate schedule, we can infer that they have the same average flight propensity and should be given equal bail. If rate schedules are identical, the entire bail disparity between minority and white males is unjustified. The difference between white and minority bail amounts thus directly indicates the extent of racial discrimination. Even if judges could constitutionally make racial inferences about flight propensity, such inferences should not lead to higher bail amounts for minorities. ${ }^{106}$

Our analysis in Appendix B further indicates that flight schedules for black and Hispanic women are significantly lower than for white males. This suggests that the bail amount which equalizes flight probabilities is lower for minority women than for white men. This result roughly justifies the lower bail amounts set for Hispanic women. It also suggests that the 7.5 percent higher bails black women receive were 15 percent too high. ${ }^{107}$

Our estimates of the rate schedules also provide evidence that bail deters flight. The elasticity of the bond rate with respect to the bail amount is -0.527 , which indicates that bond fees increase as bail increases. For example, if bail is increased 10 percent, the bond rate should only fall by about 5.3 percent, causing the fee amount (the product of bail amount and bond rate) to rise. ${ }^{108}$

\section{NONDISCRIMINATORY EXPLANATIONS}

To reach our conclusion that the disparate bond rate test provides evidence that bail setting subjects minority male defendants to an unjustified disparate impact, we needed to make three crucial assumptions:

104. See text accompanying notes $184-190$ infra.

105. The fourth column in Table 8 in Appendix $B$ indicates that the t-statistics associated with the race coefficients are not statistically different from zero. This means that race has a statistically negligible effect on bond rates once bail amounts are included in the regression.

106. These regressions were constrained to estimate a single flight elasticity for all defendant race-gender types. We investigated whether the rate schedules for minority defendants had different slopes than for white defendants. In separate regressions we found no statistical difference in the slopes (or intercepts) of the rate schedules of white and minority defendants.

107. Recall from Table 3 that black women face bail amounts that are $7.5 \%$ higher than for white men (although this result is not statistically significant). See text accompanying note 86 supra.

108. The sign and statistical significance of the offense severity and offense category variables imply that defendants with more serious offenses receive higher bond rates, indicating that serious offenders have higher flight propensities. For instance, drug, gun, and larceny have significantly higher flight schedules than the omitted category. This suggests that judges are rational in setting higher bail for more serious crimes. Judges do seem to overshoot, however, increasing bail more than the underlying offense characteristics merit. 
(1) The Proportionality Assumption: defendants' bond rates are proportional to their probability of flight;

(2) The Equalization Assumption: the only legitimate goal of bail setting is to equalize the probability of appearance for all defendants who are released; and

(3) The Sample Selection Assumption: defendants who are released on bail bonds constitute a representative sample of those receiving bail as a condition of release.

The proportionality assumption insures that lower minority bond rates actually indicate a lower risk of flight. The equalization assumption permits us to conclude that the disparate impact against minority male defendants is unjustified. ${ }^{109}$

The third and final assumption concerns sample selection. The population of defendants who obtain release using bail bonds is only a subset of all defendants for whom bail is set. Some defendants who receive bail as a condition of release never make bail and remain in jail pending trial. Others gain release by posting their own assets. If the defendants who secure release by employing the services of bond dealers do not constitute a representative sample of all defendants receiving bail, our inference of discrimination may not be valid.

The following section critically examines each of these three assumptions and the variety of ways in which they might fail. Specifically, we examine possible market distortions affecting the proportionality assumption, possible alternative judicial goals, and possible selection biases. We offer three classes of alternative hypotheses that could provide nondiscriminatory explanations for the results summarized in Table 3 . We conclude, however, that these nondiscriminatory explanations cannot completely account for the racial disparities in bail setting and bond rates.

\section{A. Market Forces that Might Cause Bond Rates not to Reflect Flight Probabilities}

Factors which undermine the proportionality of bond rates and flight probabilities could provide an alternative (nondiscriminatory) explanation for the lower bond rates black males receive. If bail rates diverge from flight probabilities, then minority defendants might receive lower bond rates even if judges set bail amounts so as to equalize the probability of flight. This section examines whether competition forces bond prices to reflect expected cost and whether expected cost is proportional to the probability of flight. Competition may not force bond prices to reflect costs if bond dealers engage in various forms of price discrimination. Furthermore, costs might not be proportional to the probability of flight because of differences in the forfeiture rates and collat-

109. For example, if judges could legitimately set higher bail for defendants they suspect might commit further crimes pending trial, then our evidence that bail setting does not equalize flight probabilities across defendants would not rule out the possibility that disparate bail levels were justified by this alternative goal (which the bail bond market does not "price"). 
eral for various types of defendants, as well as because of the effect of dealer search and monitoring costs.

\section{Price discrimination.}

A possible alternative explanation for the lower bond rates we observe for minority bailees could be that bond dealers in New Haven engage in price discrimination. If bond dealers have sufficient market power to charge supracompetitive prices, they might find it profitable to charge higher fees to richer defendants. Under this theory, minority defendants might encounter lower rates simply because they are more likely to have a lower ability to pay. ${ }^{110}$

We conclude, however, that bond dealers in New Haven did not discriminate on the basis of defendants' ability to pay. As observed earlier, low bond rates in towns like New Haven are more closely associated with a town having many dealers than with a town having significant poverty, ${ }^{111}$ and monopolist and duopolist bond dealers in other Connecticut towns find it unprofitable to price discriminate based on the ability to pay. ${ }^{112}$ The first finding suggests that bond dealers may not have sufficient market power to raise price above cost, while the second suggests that even bond dealers who do have market power do not choose to discriminate based on ability to pay.

If bond dealers did price discriminate on the basis of defendants' ability to pay, we would expect the difference between white and minority bond rates to be more marked with large bail amounts for which the bond dealer's fee is more substantial. Yet, racial differences in rates persist over the entire range of bails. Table 4 shows average rates paid by white and minority defendants, the raw differences between the rates, and the adjusted percent rate differences, sorted by size of bail. As the adjusted percent difference column indicates, nonwhites generally pay lower rates in all bail ranges. For bail amounts of $\$ 1000$ or less, for which the maximum fee is $\$ 100$, white men pay an average of $\$ 63$ and black men pay an average of $\$ 52$. It is unlikely that black men can pay bond dealers $\$ 52$, but not $\$ 63$. The persistence of the racial discount for even small bail amounts indicates that racial disparity in bond rates cannot be fully explained by differences in ability to pay. 113

The racial disparity in bond rates might, however, be caused by a different type of price discrimination. Bond dealers may charge higher prices to defendants who have higher search costs or poor information about competitive offers. If white defendants have disproportionately high search costs, bond dealers may have de facto monopoly power over any white defendant who solicits a

110. Note that if bond dealers discriminate against minority defendants on the basis of race, our market evidence is particularly powerful, because minority bond rates would have been even lower if blacks had encountered nondiscriminatory pricing.

111. See text accompanying notes $75-76$ supra.

112. See text accompanying note 77 supra.

113. An analysis of bonds written by individual bond dealers also indicates that New Haven bond dealers compete for the business of all defendants-regardless of race. A chi-squared test showed white and minority defendants were distributed randomly among bond dealers, suggesting that individual bond dealers did not specialize in serving defendants of a particular race. 
TABLE 4

Average Rates for Different Bail Sizes

\begin{tabular}{|c|c|c|c|c|c|}
\hline Bail range & White & $N$ & Minority $^{a}$ & $\mathbf{N}$ & Adjusted \% \\
\hline $0-1000$ & $\begin{array}{c}8.86 \% \\
(2.08)\end{array}$ & 164 & $\begin{array}{r}8.68 \% \\
(3.14)\end{array}$ & 463 & $-7.1 \%^{* *}$ \\
\hline $1001-2500$ & $\begin{array}{c}7.53 \% \\
(2.24)\end{array}$ & 54 & $\begin{array}{r}6.78 \% \\
(2.29)\end{array}$ & 157 & $-9.9 \%^{*}$ \\
\hline $2501-5000$ & $\begin{array}{l}7.82 \% \\
(2.32)\end{array}$ & 30 & $\begin{array}{l}5.85 \% \\
(2.02)\end{array}$ & 106 & $-27.7 \%^{* *}$ \\
\hline $5001+$ & $\begin{array}{l}5.69 \% \\
(2.43)\end{array}$ & 12 & $\begin{array}{r}4.27 \% \\
(1.59)\end{array}$ & 132 & $-3.2 \%$ \\
\hline \multicolumn{6}{|c|}{ 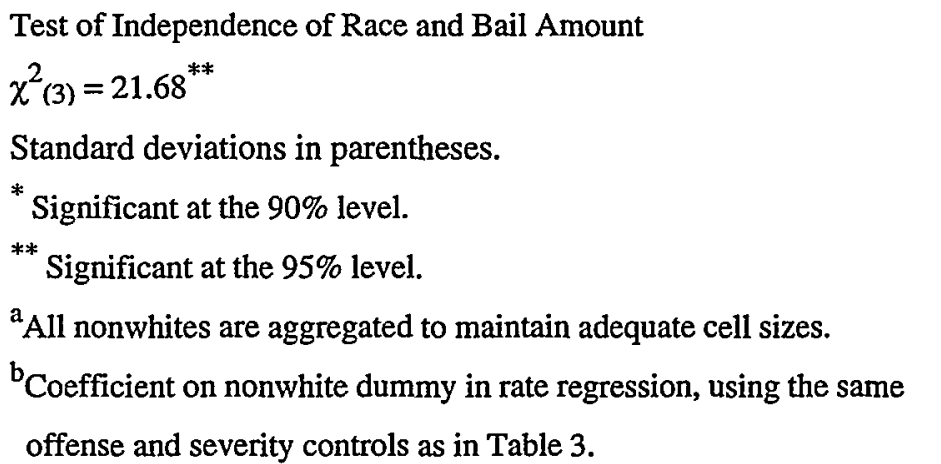 } \\
\hline
\end{tabular}

bond dealer. This difference in search costs could lead bond dealers to charge lower rates to minority defendants, who would be more likely to search for better offers. ${ }^{114}$

114. The possibility of search cost- or information-based price discrimination is an important concern. Previous work by one of the authors indicates that these types of price discrimination can persist even in markets with very large numbers of competitors. Ayres, supra note 15 (finding that car dealerships in the Chicago area routinely charge blacks and women higher prices, despite the existence of about 500 competing dealerships in the area); Ayres \& Siegelman, supra note 15 (same).

Black male defendants may have lower search costs than white defendants if black males in New Haven are more likely to have experience with the criminal justice system. This possibility is suggested by studies showing that nationally $23 \%$ of black men between the ages of 20 and 29 are either in prison, jail, on probation, or on parole on any given day, compared to only $6.2 \%$ of whites in the same age group. Mark Mauer, The Sentencing Project, Young Black Men and the Criminal Justice System: A Growing National Problem 3 (1990). A search-cost explanation is consistent with our earlier finding in Table 2 that bond dealers charged uniformly high prices in poor Connecticut towns such as New London. Even if minority defendants had lower costs of search, they would not receive lower rates in duopoly markets (where all search is in vain). 
While we have presented evidence which tends to disprove "ability to pay" discrimination, we cannot exclude the possibility that dealers discriminate based on differences in search costs or information. Indeed, if minority defendants in our sample have more prior experience with the criminal justice system, then minority defendants may have better information about competitive pricing and may be able to search more easily for competitive bail fees.

\section{Dealer search and monitoring costs.}

Even if competition forces bond dealers to set their fees equal to their expected costs, the presence of search and monitoring costs could prevent bond rates from being proportional to flight probabilities. As shown in Appendix A, competitive prices might reflect not only the risk of bond forfeiture, but also the expected costs of monitoring defendants and attempting to recapture defendants who flee. ${ }^{115}$

Search and monitoring costs might provide an alternative explanation for disparate bail rates. If bond dealers believe that white defendants would be more costly to monitor or search for, then the minority defendants may be offered lower bond rates than white defendants with equal flight probabilities. Several factors diminish - but do not eliminate-the plausibility of this alternative type of explanation. First, as an empirical matter, bond dealers report that search costs are not an important determinant of bond fees. ${ }^{116}$ Thus, it is unlikely that differences in search costs could explain the widely disparate bond rates. Second, it is unlikely that it is significantly easier for bond dealers to monitor the whereabouts of minority defendants because the bond dealers in our sample, all of whom are white, reported reluctance to drive into some of the predominantly minority neighborhoods (e.g., to pick up and escort defendants to a court date). Thus, even though monitoring and search costs could potentially undermine our proportionality assumption, these costs, as an empirical matter, are not significant enough to account for the racial disparity in bond rates.

\section{Forfeiture rates.}

The forfeiture rate is the proportion of bail that the bond dealer forfeits when a defendant fails to appear. If the forfeiture rate were lower on average for black defendants than for white defendants, then bond dealers might charge black defendants lower bond rates because bond dealers would incur relatively less risk. In particular, if the percentage forfeiture declines with the bail size, then black male defendants may have lower forfeiture rates and therefore lower

115. For example, if ex ante monitoring was completely efficient in deterring flight, then competitive bond rates would only reflect expected monitoring costs and would have no relation to the constant (zero percent) probability of flight.

116. See text following notes 182-183 infra. Moreover, in Appendix A, we show that the proportionality assumption continues to hold if ex ante monitoring is proportional to the amount of bail at risk. 
bond rates, because they face higher bail amounts on average than do white males. ${ }^{117}$

Accordingly, we investigated whether the size of the forfeiture rate varies with the bail amount. We found that the forfeiture rate is a constant 55 percent, regardless of the bail amount. ${ }^{118}$ This result is consistent reports from local prosecutors, who indicated that the forfeiture rate was a uniform 50 percent. Thus, differences in forfeiture rates apparently cannot explain the lower bond rates charged to black and Hispanic males.

\section{Collateral.}

Because the value of the collateral posted by the defendant reduces a bond dealer's risk, racial differences in posted collateral could, in theory, account for differences in bond rates. However, we find that differences in collateral also fail to account for the racial disparities in bond rates. As an initial matter, racial differences in posted collateral might easily strengthen our confidence in our findings of race discrimination. Because racial minorities are more likely to be poor, we might expect minority defendants to post less collateral than white defendants. If this is so, bond rates for white defendants should be lower than bond rates for minority defendants. This would indicate that our findings actually understate the true amount of discrimination. ${ }^{119}$

117. The average bail amounts, by race and gender, in our sample were:

\begin{tabular}{|lccc|}
\hline \multicolumn{4}{|c|}{ Average Bail Amounts by Race and } \\
& Gender & \\
Defendant Type & Mean & Std. Dev. & N \\
\hline White Male & 1978 & 2755 & 210 \\
Black Male & 4446 & 8117 & 596 \\
Hispanic Male & 3624 & 6486 & 118 \\
White Female & 1780 & 2345 & 60 \\
Black Female & 2271 & 4201 & 128 \\
Hispanic Female & 1421 & 2549 & 16 \\
\hline
\end{tabular}

If the fraction forfeited declines with the bail amount, there will also be a negative relationship between the rate paid and the bail amount, even if bail has no deterrence effect.

118. The forfeiture rate is set by the prosecutor. We have 1990 data on 31 bond forfeitures in New Haven. Using regression analysis, we estimated the relationship between the amount forfeited and the bail amount to be:

$\mathrm{F}_{\mathrm{i}}=0.55\left(\mathrm{~B}_{\mathrm{i}}\right)^{1.01}$ where $F_{i}$ is the amount forfeited on defendant i's bail $\left(B_{i}\right)$. Because the exponent 1.01 is not statistically different from 1 , the equation is linear in $B_{i}$.

119. Criminal defendants do not, however, represent a random cross-section of the population. While minorities are generally more likely to be poor, it is possible that, within the class of criminal 
Our data set does not contain information on collateral amounts. However, both anecdotal and ancillary empirical evidence indicate that collateral effects are not a serious concern. Bond dealers in New Haven often write bonds without any collateral requirements. According to a major New Haven bond dealer, the most common form of "collateral" is the signatures of the defendant's relatives. ${ }^{120}$ Although some defendants deposit titles to cars and houses and occasionally jewelry and other personal objects as collateral, this particular bond dealer claims that his net proceeds from collateral are close to zero. Bond dealers almost never foreclose on collateral, for a variety of reasons. First, collection is costly. Second, collateral may have private value to the defendant, but lack sufficient market value to warrant collection. ${ }^{121}$

Table 4 provides further evidence against the hypothesis that differences in collateral induce the disparate pattern of bail and bond rates. Even in the subsample of defendants with bail of $\$ 1000$ and below, we find that the average rate for minority defendants is 7 percent less than for white defendants. The fact that collateral is rarely collected for small bail amounts suggests that differences in collateral cannot explain the results. ${ }^{122}$

\section{Fixed costs.}

In theory, bond dealers might charge lower rates to minority defendants because a dealer's fixed cost of writing a bond could be amortized over the larger fees charged minority defendants with higher bail amounts. But fixed costs are unlikely to figure prominently in bond pricing, because unlike other professionals, bond dealers do not maintain offices dedicated to their businesses. ${ }^{123}$ Consequently, we expect that bond dealers' average fixed costs are not high enough to significantly affect the rates they charge, even for relatively small bail amounts.

Moreover, allowing for fixed costs actually strengthens our finding of disparate impact. After accounting for the presence of fixed costs, ${ }^{124}$ we find that

defendants, minorities could happen to have a greater ability to pay. If, under this scenario, minority defendants post proportionately more collateral than whites, then minorities would pay lower rates, not only because they may be less likely than whites to disappear, but also because their disappearance costs bond dealers less.

120. Interview with Robert Jacobs.

121. See note 49 supra. Freed and Wald report several anecdotes of idiosyncratic collateral:

A D.C. bondsman [once took] a lap dog as collateral. A story current among bondsmen in Florida is that one of their number used to carry a collateral box in which he collected items of sentimental value, such as wedding rings, or of practical value, such as false teeth. On one occasion he is supposed to have kept the child of the accused.

FREed \& WALD, supra note 3 , at 27.

122. One study found that bond dealers collected collateral in only $5-10 \%$ of their cases and concluded: "These are probably cases involving more serious offenses and thus higher bail amounts." Dill, supra note 77 , at 663 .

123. Bond dealers may, however, bear fixed administrative costs (e.g., paperwork) in taking on each defendant.

124. If the fee includes a fixed cost component, we can estimate fixed costs (FC) from a rate regression as the coefficient on $(1 / B): r_{i}=X_{i} \beta+F C(1 / B)+\varepsilon_{i}$. Running this regression, we estimate FC to be $\$ 18.87$ (with a standard deviation of $\$ 0.87$ ). Using judge dummies as instruments to correct for the endogeneity of bail in $(1 / B)$ (as we did in obtaining the results summarized in Table 8 infra), we estimate FC to be $\$ 32.22$ (with a statistically significant $t$-statistic of 5.95 ). 
the percentage racial rate disparity actually becomes larger and more significant. ${ }^{125}$ Therefore, while bond dealers may incur fixed costs, these costs do not provide an alternative explanation for the racial disparity in bond rates. ${ }^{126}$

While the above section casts doubt on a variety of factors that might cause the bond rate to diverge from the defendant's probability of flight, our analysis has not been exhaustive. For example, even if bond dealers accurately price the defendant's flight risk, judges may be more concerned about a different contingency: Judges may care about inducing a timely appearance at a scheduled court date, while bond dealers may care only about whether the defendant will remain at large for six months-because only then do they risk forfeiture.127 Even though we have presented a number of arguments to support our general contention that bond rates will broadly reflect a defendant's probability of flight, we are most concerned by the possibility that bond dealers discriminate on the basis of the defendant's ability to search for a competitive price, or that bond dealers have racially disparate costs of monitoring a defendant's whereabouts or searching for a defendant after a failure to appear. In sum, our results should only be relied upon with appropriate caution. ${ }^{128}$

\section{B. Alternative Judicial Goals}

While we have assumed that the only legitimate criterion judges may consider in setting bail is equalizing the probability of appearance for all defendants, a number of commentators have suggested that judges apply other criteria. ${ }^{129}$ In this section we consider four alternative motivations for bail setting:

(1) targeting higher probabilities of appearance for more severe offenses;

(2) avoiding racially based inferences;

125. This is not surprising, because minorities pay lower bond rates than whites. If we subtract a fixed amount from all fees, the racial disparity (in percentage terms) becomes even larger.

126. Furthermore, assuming that white and minority defendants may impose differing fixed costs on dealers cannot account for this finding. In fact, we estimate that minorities have higher fixed costs (although the difference is insignificantly small when we instrument for $(1 / B)$ ), which suggests that minorities should pay somewhat higher rates than whites with the same flight probabilities. If anything, this strengthens our finding of discrimination against minorities.

127. The possibility that judges and bond dealers might have divergent concerns figured prominently in Malcolm Feeley's study of the New Haven courts. See FeELEY, supra note 14, at 224-29 (describing continuances and other accommodations that could attenuate the relationship between failure to appear and bond forfeiture).

128. Before leaving this section, we note that although the disparate rate test hinges on the proportionality of bond rates paid and flight probabilities, the rate schedule test remains valid even if the factor of proportionality between cost and flight probability varies with the bond amount, as long as this variation is the same for whites and minorities. For example, if the ratio of required collateral to bail varies with the bail amount, bond rates will not be proportional to flight probabilities. However, if bond dealers require the same relationship between collateral and bail for all defendants, the rate schedule test (discussed in Appendix B) remains valid. While minority and white defendants with the same flight probabilities could have different rates because of differing bail amounts, the estimated rate schedule controls for differences in bail amounts. Thus, the rate schedule test would show whether blacks and whites have different underlying flight tendencies warranting different bail treatment regardless of the effect of differing bail amounts.

129. See, e.g., FREED \& WALD, supra note 3, at 9-21. 
(3) deterring pretrial misconduct; and

(4) targeting a desired bond fee instead of a desired probability of appearance.

It should be emphasized that only the first two of these criteria were even arguably consistent with Connecticut state law as of the time our data was collected. ${ }^{130}$ Consequently, even if courts set bail to deter pretrial misconduct or to induce a desired bond fee, our disparate rate test still provides evidence of unjustified disparate impact during that period. Under these alternative assumptions, minority males in our sample were injured by bail-setting criteria that contravened existing state law. ${ }^{131}$

\section{Targeting higher probabilities of appearance for more serious offenses.}

Although the Connecticut statute mandates that bail be set to "reasonably assure the appearance of the arrested person in court,"132 courts may interpret the statute to demand a higher degree of assurance for more serious offenses. Judges may feel that a reasonable assurance of appearance in a murder case mandates no more than a 5 percent chance of flight, while a 7 percent chance of flight may be tolerable in a simple larceny case. ${ }^{133}$ Our finding that bond rates are lower for more serious offenses may be consistent with such an interpretation of the Connecticut statute. If courts in fact demand a higher probability of appearance for more serious categories of crime, the fact that minorities pay

130. During the last three months of our sample period, an amendment to the Connecticut bail statute permitted courts to set higher bail amounts to deter certain types of pretrial misconduct, but this option was almost never used. See note 60 supra (discussing the amendment and why it did not affect the data). The second criterion, as discussed below, might flow from the state or federal Equal Protection Clauses. See text accompanying notes 137-142 infra.

131. Our assertion that equalizing flight probabilities was the only legitimate goal of bail setting puts tremendous weight on the supremacy of the statute. Preventive detention is a constitutionally permissible objective for bail setting. Some might argue that it was legitimate for judges to set bail on this basis even though that would contravene a statutory mandate.

132. Conn. Gen. Stat. Ann. § 54-64a(a)(1) (West Supp. 1993).

133. This interpretation might be consistent with the traditional notion that more serious crimes must be deterred with harsher penalties and/or a higher probability of punishment. Achieving a higher likelihood of appearance enhances the probability that the defendant will be punished. 
lower bond rates might be explained by a tendency of black defendants to commit more serious crimes. ${ }^{134}$

To control for this possibility, we tested for racial disparities in bail and bond rates within individual offense categories. ${ }^{135}$ Table 5 reports the results for the two largest offense categories: assault and drug offenses. These results indicate that, even within individual offense categories, minority men (and for drug offenses, black women as well) pay lower bond rates. Judges seem to demand lower flight probabilities for more serious offense categories, but even controlling for this propensity, bail set for minority defendants is unjustifiably high. ${ }^{136}$

134. There is no clear evidence, however, that minority defendants are more likely to commit more serious offenses. The distribution of offense severities for minority and white defendants was:

\begin{tabular}{|lcc|}
\hline Offense Severity & Minority & White \\
\hline Class A or B Felony & $4.0 \%$ & $3.5 \%$ \\
Class C or D Felony & 14.2 & 15.0 \\
Class U Felony & 32.0 & 32.7 \\
Class A or B Misdemeanor & 40.8 & 41.5 \\
Class C or D Misdemeanor & 6.6 & 5.0 \\
Other & 2.1 & 2.3 \\
Total & 858 & 260 \\
\hline
\end{tabular}

Although minority defendants are somewhat more likely to have committed Class A and B felonies, they are less likely than white defendants to be charged with other types of felonies. However, none of these differences is statistically significant. An analysis of particular offense types similarly reveals that, with the exception of firearm offenses, minority defendants do not commit serious offenses more frequently than whites.

135. This approach assures that results are not skewed by overrepresentation of minority defendants in serious offense categories.

136. The bond rate disparities within offense categories might still have been caused by our failure to adequately control for aspects of offense severity which are correlated with minority status. It is also possible that judges care not only about their estimate of a defendant's flight probability but also about their confidence in this estimate. In statistical parlance, the bail setters might legitimately take into account not only their estimate of a defendant's flight probability, but also the variance of this estimate. In particular, judges might legitimately target a lower expected flight probability if they are less confident about their estimate. If judges are more uncertain about minority defendants' propensity to flee, they might demand a higher probability of appearance, much as investors demand higher expected returns on assets that bear high risks.

Bond dealers are likely to be just as uncertain about minority defendants' flight propensities under this scenario. However, because some dealers write hundreds of bonds each year, they may be able to diversify away the additional risks associated with minority defendants. Uncertainty will not contribute to rate disparity if judges are also able to diversify away risks. 
TABLE 5

Bail and Rate Regressions by Offense

(SUR Estimation)

\begin{tabular}{|c|c|c|c|c|}
\hline \multicolumn{5}{|c|}{ Drug Offense } \\
\hline & \multicolumn{2}{|c|}{ Log Bail Amount } & \multicolumn{2}{|c|}{ Log Rate Paid } \\
\hline & coefficient & t-stat. & coefficient & t-stat. \\
\hline CONST & 6.440 & 20.442 & -2.499 & -21.835 \\
\hline \multicolumn{5}{|c|}{ Defendant Characteristics } \\
\hline BM & $1.109^{* *}$ & 6.40 & $-0.439^{* *}$ & -6.97 \\
\hline $\mathrm{HM}$ & $0.704^{\neq *}$ & 2.62 & $-0.166^{*}$ & -1.70 \\
\hline WF & -0.175 & -0.46 & 0.026 & 0.18 \\
\hline $\mathrm{BF}$ & 0.495 & 1.60 & $-0.225^{* *}$ & -1.99 \\
\hline $\mathrm{HF}$ & -0.195 & -0.34 & -0.065 & -0.31 \\
\hline $\mathrm{R}^{2}$ & 0.219 & & 0.219 & \\
\hline $\mathbf{N}$ & 264 & & 264 & \\
\hline \multicolumn{5}{|c|}{ Assault } \\
\hline & \multicolumn{2}{|c|}{ Log Bail Amount } & \multicolumn{2}{|c|}{ Log Rate Paid } \\
\hline & coefficient & t-stat. & coefficient & t-stat. \\
\hline CONST & $6.756^{*}$ & 50.42 & $-2.437^{*}$ & -45.43 \\
\hline \multicolumn{5}{|c|}{ Defendant Characteristics } \\
\hline BM & -0.093 & -0.62 & $-0.148^{*}$ & -2.47 \\
\hline $\mathrm{HM}$ & 0.121 & 0.57 & $-0.150^{* *}$ & -1.77 \\
\hline WF & -0.541 & -0.63 & c.135 & 0.39 \\
\hline BF & -0.091 & -0.41 & -0.060 & -0.68 \\
\hline HF & -0.284 & -0.64 & 0.010 & 0.06 \\
\hline $\mathrm{R}^{2}$ & 0.375 & & 0.130 & \\
\hline $\mathbf{N}$ & 220 & & 220 & \\
\hline \multicolumn{5}{|c|}{$\begin{array}{l}\text { * Significant at the } 90 \% \text { level. } \\
\text { ** Significant at the } 95 \% \text { level. } \\
\text { Offense severity variables were included in these regressions but } \\
\text { are not reported to save space. }\end{array}$} \\
\hline
\end{tabular}




\section{Color-blind bail setting.}

Attempts to comply with the equal protection provisions of the Connecticut and federal constitutions might also provide a nondiscriminatory explanation for disparate bond rates. ${ }^{137}$ If these constitutional mandates force courts to ignore racial inferences that would indicate lower flight propensities (e.g., for black women), courts would be compelled to set bail higher than these defendants deserve under a pure equalization standard.

\section{FIGURE 3}

Color Blind Bail Setting Can Induce

Lower Minority Bond Rates

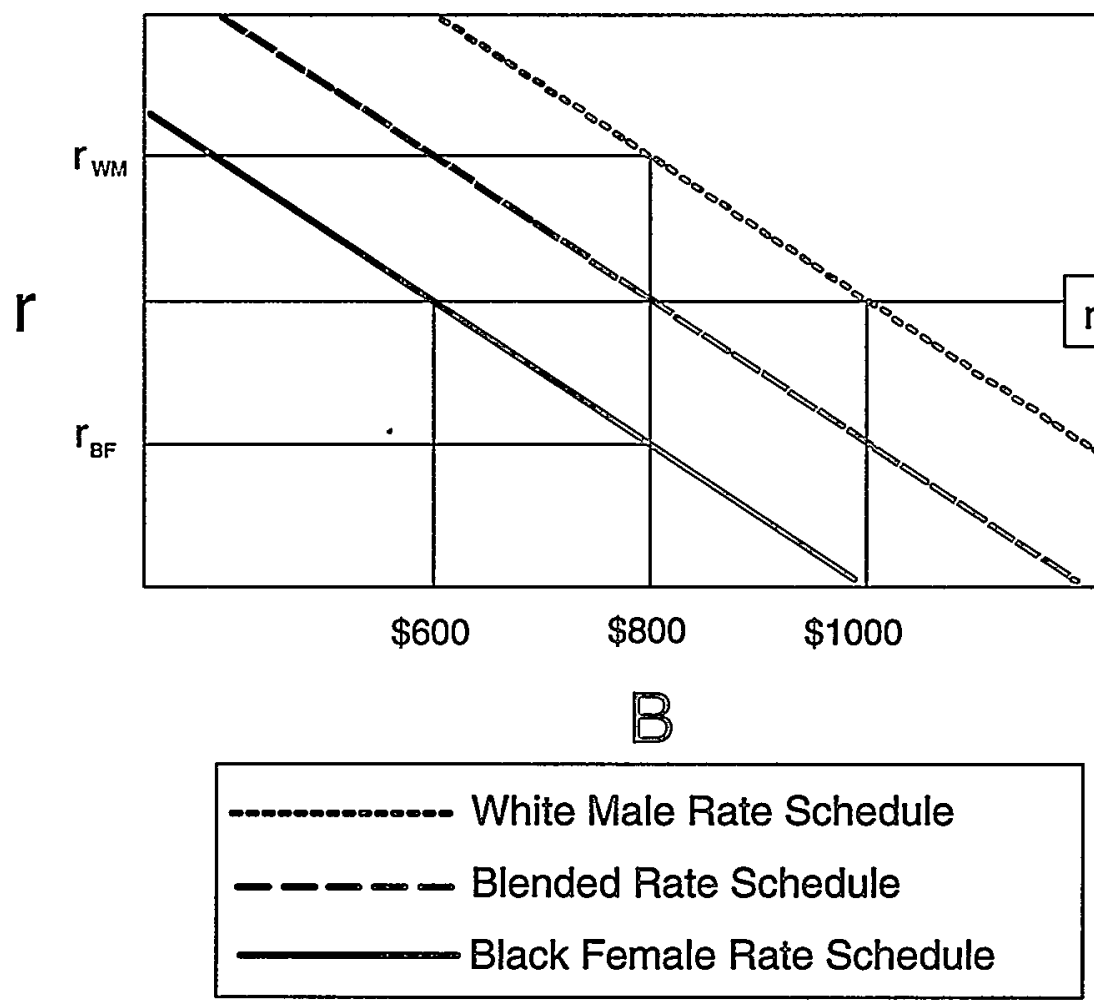

Figure 3 illustrates the possible impact of color-blind bail setting. The figure illustrates our earlier evidence that black female defendants have a 7.5 percent lower flight propensity than white male defendants. ${ }^{138}$ A judge forced to

137. The Equal Protection Clause of the Fourteenth Amendment reads: ". . . nor [shall any state] deny to any person within its jurisdiction the equal protection of the laws." U.S. CoNST. amend. XIV. The Connecticut state constitution reads "[a]1l men when they form a social compact, are equal in rights; and no man or set of men are entitled to exclusive public endowments or privileges from the community." ConN. ConsT. of 1965 art. I, § 1.

138. See Table 8 infra. This result was only significant at the $90 \%$ level. Table 8 also indicates that Hispanic female defendants had a $19 \%$ lower propensity to flee (with $95 \%$ significance). 
ignore racial inferences for equal protection reasons would have to set bail only on the basis of the average or blended flight propensity for the entire population of defendants of all races and genders. ${ }^{139}$ The judge would thus have to set the bail at a level that would induce the requisite probability of appearance for the average defendant, which in Figure 3 is depicted as $\$ 800.140$ The effect of setting the same bail for all defendants (even though black females have a lower propensity to flee) is that black females will be overdeterred from flight, and white males will be underdeterred. ${ }^{141}$ If bond dealers can discriminate on the basis of race and gender, they will charge black female defendants lower rates than white male defendants, as depicted in Figure 3 by the equilibrium rates $\mathrm{r}_{\mathrm{BF}}$ and $\mathrm{r}_{\mathrm{WM} \cdot} \cdot{ }^{142}$

Two important pieces of evidence contradict the color-blindness theory, however. First, Table 8 indicates that the flight schedule for minority male defendants is not statistically different than the flight schedule for white males, suggesting that, as an empirical matter, race is not a valid predictor of defendants' propensity to flee. Color-blind adjudication therefore cannot explain the disproportionately low bond rates for minority males. Second, color-blind bail setting should cause black females and white males to receive the same bail amount. Table 3 indicates, however, that after controlling for several other variables, bail is set significantly higher for black females than for white males.

139. The average flight propensity would depend on the relative proportion of black, Hispanic, and white defendants of each gender in the population of defendants.

140. The judge in this scenario is analytically in the same position as an issuer of pension annuities after City of Los Angeles v. Manhart, 435 U.S. 702 (1978). Because Title VII prohibits discrimination in the pricing of annuities, an issuer cannot charge women more than men on the grounds that women live longer. Accordingly, the issuer must price annuities based on the blended life expectancy of men and women in the annuity pool. See George J. Benston, The Economics of Gender Discrimination in Employee Fringe Benefits: Manhart Revisited, 49 U. CHI. L. REv. 489, 536-37 (1982).

John Goldkamp describes a similar difficulty with ignoring race and gender effects when constructing other criminal guidelines:

Guidelines critics have noted instances when attempts were made to eliminate the effects of status variables merely by dropping the obnoxious factors from the equation and then rerunning the new equation.... [T] [Te effects of the status variables will not be removed in this fashion because the remaining predictors in the new equation will change their weights; in effect, the weight of the purged variables will be redistributed among other seemingly neutral variables.

John S. Goldkamp, Prediction in Criminal Justice Policy Development, in 9 Prediction and ClassiftCation: Criminal Justice Decision Making 103, 138 (D. Gotfredson \& M. Tonry eds., 1987); see also Franklin M. Fisher \& Joseph B. Kadane, Empirically Based Sentencing Guidelines and Ethical Considerations, in 2 Research on SENTENCING: THE SEARCH For REForm 184, 192 (Alfred Blumstein, Jacqueline Cohen, Susan E. Martin \& Michael H. Tonry eds., 1983).

141. Figure 3 indicates that, in order to induce equal probabilities of appearance, judges would need to set bail at $\$ 600$ for the black females and at $\$ 1000$ for white males.

142. As in the Manhart context, discussed in note 140 supra, prohibiting the decisionmaker from acting upon relevant predictors causes one group to subsidize another. In this bail example, color-blind bail setting forces the judge to set the bail too high for black females and too low for white males. As discussed above, since the bond rate is almost always inelastic with respect to the bail amount, colorblind bail setting would increase the cost of pretrial release for black female defendants and lower the cost for white male defendants. See note 103 supra and accompanying text. The black females' lower flight propensity would subsidize the cost of white males' pretrial release, because the presence of black females in the population lowers the average bail that white male defendants would need to post. 
Thus, the available empirical evidence is not consistent with the hypothesis that judges' attempts to ignore race in setting bail caused disparate bond rates.

\section{Deterring pretrial misconduct.}

A third alternate goal that courts may be pursuing in setting bail is reducing the incidence of pretrial crime. Such a goal might further the traditional aim of specific deterrence, but would clearly violate the governing state statute. ${ }^{143}$ In the 1980s, however, the United States Supreme Court significantly expanded the power of states to use pretrial detention to prevent arrestees from committing crimes before trial. ${ }^{144}$ The Connecticut Supreme Court more recently argued that preventive detention is constitutionally permissible, ${ }^{145}$ and the Connecticut legislature amended the statute governing bail setting procedures to authorize courts to use bail to "reasonably assure ... that the safety of another person will not be endangered."146

While courts in setting bail may be concerned about the risk of pretrial crime, this risk will not be reflected in bond rates because the bond dealers' payoffs do not depend on whether the defendants commit additional crimes. ${ }^{147}$ At first glance, however, using the bail amount to prevent pretrial crime is only likely to be successful if the defendants cannot afford the bond dealer's fee. Even if judges use high bail to induce preventive detention for some high-risk defendants, this practice would not affect our sample of defendants who gained

143. See State v. Menillo, 159 Conn. 264, 269, 268 A.2d 667, 670 (1970) (the "fundamental purpose of bail is to ensure the presence of an accused throughout all proceedings"). However, the state constitution permits the court to withhold bail for capital offenses, indicating that courts may legitimately take preventive measures. ConN. ConsT. of 1965 art. I, $\$ 8$ (1988).

144. See, e.g., United States v. Salerno, 481 U.S. 739 (1987); Schall v. Martin, 467 U.S. 253 (1984); see also Marc Miller \& Martin Guggenheim, Pretrial Detention and Punishment, 75 MrNN. L. REv. 335 (1990). wrote:

145. In State v. Ayala, 222 Conn. 331, 610 A.2d 1162 (1992), the Connecticut Supreme Court

Consideration of the customary purposes of bail prior to the adoption of the constitution of 1818 supports the conclusion that while ensuring the appearance of the defendant is a primary purpose of bail in this state, it is not necessarily the sole purpose. The statutory right to bail in Connecticut is traceable to a 1672 legislative enactment declaring that "no mans person shall be Restrained or Imprisoned by any Authority whatsoever, before the Law hath sentenced him thereunto if he can put in sufficient security, bayl or mainprize for his appearance and good behaviour. ..."

610 A.2d at 1172 .

146. Conn. Gen. Stat. Ann. \$ 54-64a(b)(2) (West Supp. 1993); see also note 60 supra (discussing the negligible impact of this amendment on our data).

147. Indeed, if bond dealers believe that a defendant is likely to commit a crime while out on bail and be rearrested, it might lead the bond dealers to offer a lower rate because after rearrest the risk of forfeiture on the initial bond would be eliminated. Thus, if both judge and bond dealer believe that, if released, a defendant will ineptly rob a convenience store, the judge may be inclined to set a high bail to prevent the defendant's release, while the bond dealer may charge a lower fee because of the low risk that the defendant will not be returned quickly to jail.

It might be useful to make forfeitures contingent on pretrial crime as well as failure to appear. If courts force bond dealers to offer "pretrial crime insurance" as well as "flight insurance," bond dealers would have a greater interest in deterring pretrial misconduct. Such a reform would cause bond rates to more fully price the correct judicial goals. 
release using the services of a bond dealer. ${ }^{148}$ Only if courts failed in their attempt at preventive detention would we observe some defendants with unreasonably high bail amounts obtaining release using bond dealers. Thus, while a goal of preventive detention could clearly affect who makes bail, it does not necessarily affect the bail amounts of those people who do use a bond dealer. Moreover, even if judges set bail on the basis of this criterion, our conclusion that minority males are subjected to a disparate impact not permitted under Connecticut law stands. ${ }^{149}$

\section{Targeting desired bond fee instead of desired probability of appearance.}

Courts might also disregard the Connecticut bail-setting statute's mandate by setting bail at levels sufficient to force defendants to pay particular bond fees. As emphasized above, ${ }^{150}$ a judge targeting a minimum probability of appearance for defendants released on bail should ignore the size of the bond dealer's fee: The fee is a sunk cost that affects neither the bond dealer's monitoring and search efforts nor the defendant's incentives to appear. Judges, however, might attempt to increase the defendant's bond fee for two reasons: first,

148. It is theoretically possible that a higher bail amount that failed to induce preventive detention could still deter pretrial crime. For example, a defendant considering committing a pretrial crime and then fleeing might be deterred if her bond dealer has posted a higher bond, on the theory that the bond dealer would make a greater effort to recapture her. This would enhance the likelihood that the defendant will be caught and punished for the pretrial offense. But this kind of attenuated argument has been rejected by most commentators. See, e.g., GoldKAMp \& GotrrRedson, supra note 3, at 96 ("Any deterrent effect of bail on rearrest seems a priori less plausible, and thus the data do not seem to suggest much correspondence between the assignment of cash bail amounts and rearrest.").

149. Our theory of legal legitimacy, based as it is on the provisions of the Connecticut bail-setting statute, differs from most economic theories of legitimacy, which recognize the benefits of deterring pretrial misconduct. See, e.g., William M. Landes, The Bail System: An Economic Approach, 2 J. LeGal Stud. 79 (1973); Myers, supra note 5.

In United States v. Salemo, 481 U.S. 739 (1987), the Supreme Court upheld the constitutionality of the Bail Reform Act of 1984, which permits pretrial detention to "reasonably assure the safety of any person and the community." Justice Rehnquist, writing for the majority, reasoned that under federal law, the government has a "legitimate and compelling interest ... in preventing crimes by arrestees." Id. at 799.

We were able to construct a crude indication of whether defendants in our sample misbehaved while out on bail. Using judicial identifiers to instrument for the bail amount as previously done to obtain the results summarized in Table 8 , we found that minority males had a lower propensity to misbehave while released on bail. However, our confidence in this result is significantly weakened by our estimate in the same regression that raising the size of bail actually increases the probability of misbehavior. If this latter result were true, it would be particularly irrational for judges to increase the amounts of bail to deter pretrial misconduct unless the judges could ensure that the targeted defendants would remain in jail. Because we are highly skeptical of the estimated bail effect, we are also reluctant to place much faith in our estimate that minority males have a lower propensity to misbehave before trial.

150. See notes $67-68$ supra and accompanying text. 
in order to punish the defendant (the "punishment theory"), ${ }^{151}$ or second, to maximize bond dealers' profits (the "capture theory"). ${ }^{152}$

The punishment theory has wide support among commentators. Most notably, the title of Malcolm Feeley's pathbreaking analysis of the New Haven Court of Common Pleas heralded that "The Process Is the Punishment."153 Earlier New York City and Philadelphia studies concluded that "[h]igh bail is sometimes set to 'punish' the defendant." 154 In extreme cases, this punishment motive might cause judges to target a bond fee beyond the means of the defendant, punishing the defendant not by forcing him to pay a higher nonrefundable fee, but with pretrial incarceration. ${ }^{155}$

The capture theory is in direct conflict with our assumption that the bond market is competitive. Participants in a competitive market would have little to gain by having the bail setter raise the bail amount, because competition would bid away any supracompetitive profits, regardless of the bail amount. If the bond market is not perfectly competitive, however, bond dealers might benefit from influencing judges. For example, by setting bail above the liquid wealth of the defendant, the judge could compel a defendant to use a bond dealer to secure pretrial release (instead of posting bail personally).

Setting higher bail in a noncompetitive market might also allow bond dealers to charge higher fees. This form of capture, however, is much more likely to exist in smaller Connecticut cities with only one or two bond dealerswhere the bond dealers are already charging rates close to the statutory maximum. If bond dealers in New Haven had the market power to charge supracompetitive prices, they would not need higher bail amounts; they could simply raise their rates.

Neither the punishment nor the capture theory of fee targeting lends itself to vigorous testing. Nonetheless, neither theory can adequately explain the disproportionately low rates charged to minority males. Recall that in Table 4, when considering only specific offenses and controlling for offense severity, we found that bond dealers continued to charge minority males disproportionately low fees. Thus, even among defendants that judges might want to punish

151. One could also imagine that judges manipulate bail amounts to counteract noncompetitive pricing by bond dealers. Thus, if judges believed that bond dealers discriminated against white defendants, they might be moved to reduce the average bail of these disfavored clients. This "reverse discrimination" explanation of lower minority bond rates, however, seems at odds with our finding that minority male defendants received higher bail amounts and the fact that all the bond dealers in our sample were Caucasian.

152. Theories of "regulatory capture" predict that participants in regulated industries capture the "hearts and minds" of public officials, particularly those officials who are directly responsible for regulating industry participants. See Ian Ayres \& John Bratthwatte, Responsive Regulation: Transcending the Deregulation Debate 54, 63-71 (1992). Besides providing "flight insurance" to the state, bond dealers in various jurisdictions also provide various courtroom services. See FeELEY, supra note 14, at 102-08 (bond dealers answer questions of prosecutors and defendants in court and facilitate case flow); Dill, supra note 77, at 653-56 (bond dealers advise judges about acceptable bail, give defendants legal advice, and often encourage guilty pleas).

153. FeElex, supra note 14.

154. Ares et al., supra note 3 , at 71 .

155. The Manhattan Bail project observe this motive. See id. (noting bail was used to "break crime waves or to keep the defendant off the street until trial"). 
equally, we still find evidence of discrimination. The capture theory is also inconsistent with our finding that racially disparate bond rates persist for even bail amounts less than $\$ 500$.

\section{Sample Selection}

As noted above, ${ }^{156}$ our results are reliable only if our sample of defendants is representative of the underlying defendant population. Our sample contains only defendants who obtained pretrial release through the use of a bond dealer. It does not include two types of defendants who received bail as a condition of release: those who failed to post bail and remained in jail, and those who were released after posting their own assets. In this section, we explore how these two types of sample selection affect our interpretation of the discrimination test.

A defendant who seeks pretrial release faces three constraints that influence her ability and inclination to seek the aid of a bond dealer. The relationship between each of these constraints is depicted in Figure 4.

The first constraint is produced by regulations that cap the maximum allowable bond rates. ${ }^{157}$ The rate caps imposed by Connecticut law are denoted by a curve in Figure 4 ("Regulatory Constraint"). If, for a given defendant and bail amount, bond dealers believe that the defendant's flight risk is greater than the maximum allowed rate, they will refuse to serve the defendant. ${ }^{158}$

Even if a bond dealer is willing to offer a bail bond at a rate below the statutory maximum rate, the defendant may not be able to accept the dealer's offer if she has limited wealth. This constraint is represented by the hyperbola $r B=W$, where $W$ is the defendant's wealth (denoted in Figure 4 as the "Bond Wealth Constraint"). Thus, if the competitive bond rate for a given defendant's bail exceeds either the bond wealth constraint or the regulatory constraint, the defendant will not be offered or will not be able to accept bail bonding. Such a defendant will remain in jail and therefore be excluded from our sample. The set of defendants who remain in jail is represented by the right-hand shaded area in Figure 4.

The third constraint is the defendant's willingness and ability to post bail personally. This constraint is denoted by the vertical line in Figure 4 (denoted as the "Posting Wealth Constraint"). If the bail amount is less than the defendant's wealth, she can (but need not) post bail personally. If she plans to appear in court, she should prefer to post bail herself so long as her opportunity cost of forgone interest is less than a bond dealer's nonrefundable fee, i.e.: $i B<r B$,

156. See text following note 109 supra.

157. See note 42 supra.

158. In this way, rate regulations insure that a defendant released on bail bond will fail to appear no more than a certain percentage of the time. It is tempting to conclude that the rate regulations insure that a defendant's probability of flight will never exceed $10 \%$. However, because bond dealers forfeit only approximately $50 \%$ of the bail amount if a defendant fails to appear, the rate regulation may insure no more than a $20 \%$ probability of appearance. See text accompanying note 117 supra. Moreover, we have only claimed that bond rates are proportional to the probability of flight, so it is difficult to infer the maximum probabilities implied by the maximum rates. 
FIGURE 4

The Regulatory and Wealth Constraints that Can Limit Defendants' Ability to Purchase Bail Bonding Services

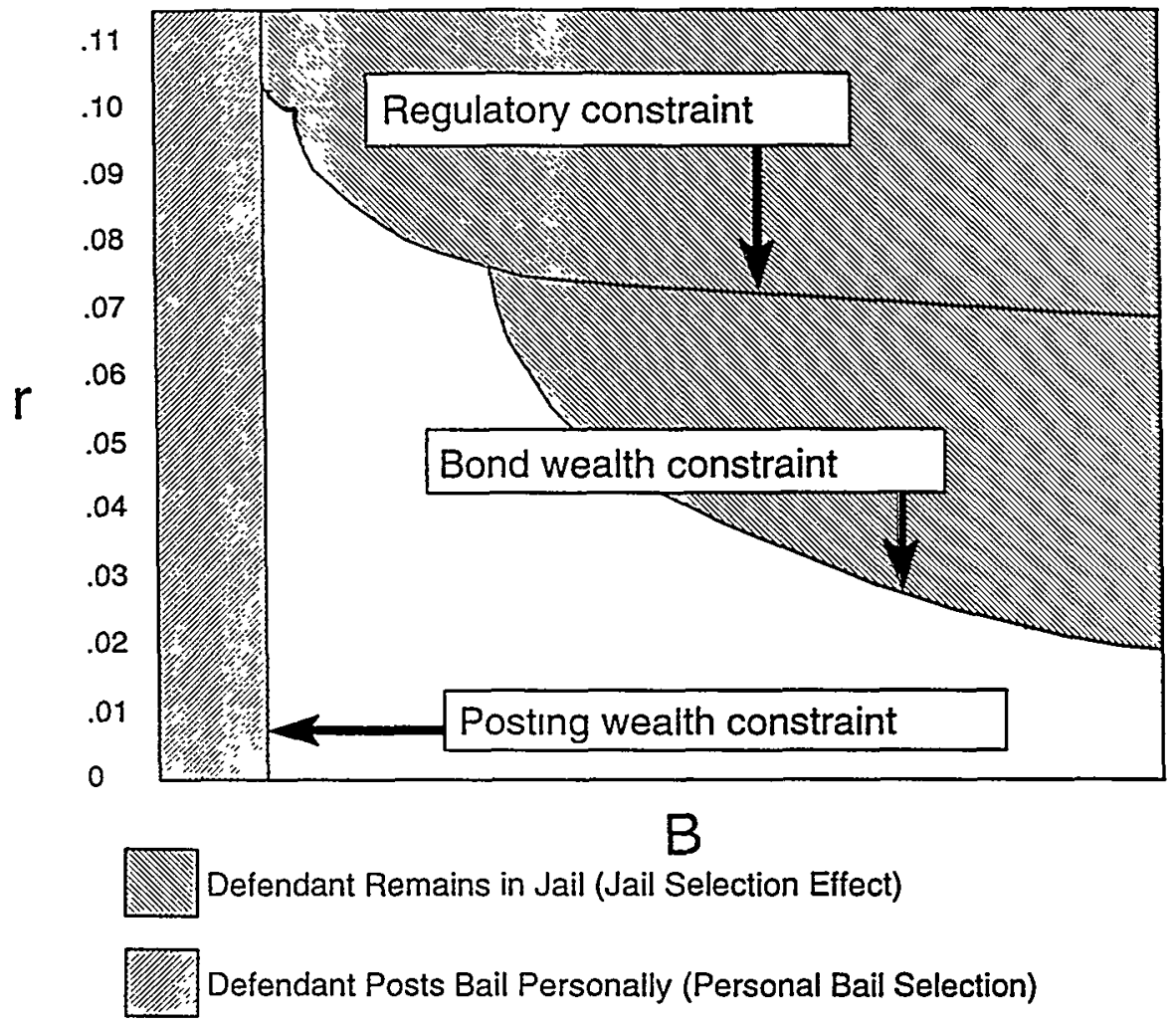

where, $B$ equals the bail amount, $i$ equals the percentage return that could be earned during the period preceding the defendant's court appearance, and $r$ equals the bail bond rate. ${ }^{159}$ This expression reduces to a determination of whether the rate of return is less than the bond rate, i.e.: $i<r$. As a practical matter, bail is normally posted for less than six months and the forgone interest is almost always less than a bond dealer's nonrefundable fee. ${ }^{160}$ In Figure 4, when a defendant is assigned a bail amount which falls to the left of (i.e., is less than) her personal wealth constraint, she should choose to post bail personally. These defendants "select" themselves out of our data set (this selection effect is depicted in Figure 4 by the shaded rectangular area).

159. More generally, if the defendant is not sure that she will appear in court, personal bonding will be less costly if:

$p B+(1-p) i B<r B+p C$.

In interpreting this equation, note that the probability of flight $(p)$ may be endogenous to the suspect's choice, because posting personal bail may more strongly deter flight.

160. For example, suspects will normally lose less interest by posting $\$ 5000$ bail personally for six months than by paying a bond dealer a typical $\$ 400-500$ fee, especially if the forgone interest would have been taxable. 
Thus, defendants may be omitted from our sample by remaining in jail, or by posting bail personally. We now explore whether either of these two selection effects might generate racially disparate bond rates.

1. Defendants who remain in jail.

Defendants who cannot afford the bond dealer's fee remain in jail and thus are excluded from our sample. If minority defendants are more frequently unable to pay such a fee, it is possible that the minority defendants who use bond dealers will pay lower rates than white defendants. To see this, suppose that a judge sets bail at $\$ 1000$ for a racially diverse group of defendants who on average have the desired probability of flight (say 10 percent). The competitive bond market responds to these $\$ 1000$ bails by offering a range of bond rates that average 10 percent. ${ }^{161}$ This scenario is depicted in Figure 5: If minority defendants are generally poorer than white defendants, only those minority defendants who receive low rate offers may have sufficient resources to accept, whereas white defendants may be able to accept the entire range of

FIGURE 5

Minority Defendants May Only Be Able to Accept Lower Rate Offers

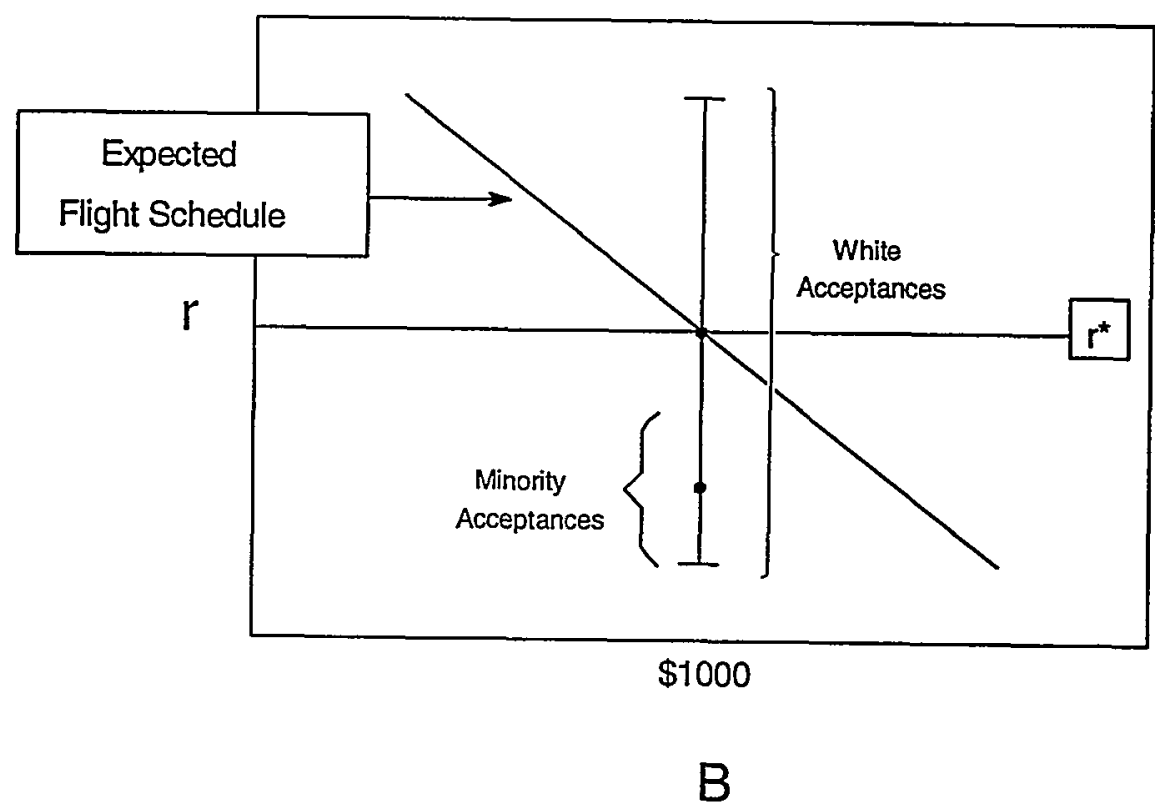

Range of Offers to Both Minority and White Defendants

161. Even a competitive bail bond market might offer a range of different rates either because some bond dealers have better information about defendants or because bond market offers are generated with some kind of random error. 
offers, even those with the highest rate. As shown in Figure 5, this selection effect may cause minority defendants to have lower bond rates than white defendants.

This type of "jail selection" is a serious empirical concern. As shown in Table 6 , in 20 percent of the cases where judges required bail, the defendants remained in jail pending disposition of their cases, and minority defendants were more than twice as likely to remain in jail as white defendants. Because our sample only includes defendants who accepted bond dealer offers, our analysis of bond rates may misstate the true relationship between rates offered and defendants' race. The size of this "jail selection effect" may be large enough to produce the bond rate disparities that we found. ${ }^{162}$

TABLE 6

Release Status of All New Haven Defendants $(N=1358)$

\begin{tabular}{|lcccc|}
\hline & & \multicolumn{3}{c|}{ Race } \\
& All & Black & White & Hispanic \\
\hline Defendant Posted Cash & $11.2 \%$ & $7.9 \%$ & $17.5 \%$ & $12.0 \%$ \\
Bail Bond & $68.8 \%$ & $68.2 \%$ & $73.3 \%$ & $62.5 \%$ \\
Defendant Remained in Jail & $20.0 \%$ & $24.0 \%$ & $9.2 \%$ & $25.5 \%$ \\
\hline
\end{tabular}

Because this form of jail selection is caused by a wealth constraint, one would expect this effect to induce the largest differences between white and minority rates at the high bail levels where affordability plays the greatest role. Yet Table 4 indicates lower bond rates for minority defendants over the entire range of bail amounts. It is unlikely that defendant wealth constraints can explain the large white-minority rate differentials observed for bail fees of less than $\$ 1000$. Nevertheless, it remains plausible that the jail selection effect could provide a nondiscriminatory explanation for part of the observed racial disparity in bond rates. ${ }^{163}$

162. The most direct way of assessing whether jail selection affects our results would be to include bona fide bond rate offers for defendants who remained in jail and assess whether the bond rates for incarcerated minorities are higher than bond rates for those using bond dealers.

163. The standard deviations of the white and minority rates provide some evidence of a jail selection effect. As Figure 5 indicates, if jail selection leads to racially disparate bond rates, we would expect there to be a lower variance in minority rates than in white rates for any given bail amount. Table 4 shows that the standard deviation for minority rates was lower than for white rates (2.02 vs. 2.32 for bail amounts between $\$ 2501$ and $\$ 5000 ; 1.59$ vs. 2.43 for bail above $\$ 5000$ ). 


\section{Posting bail personally.}

The inability of some defendants to accept bond offers may produce a jail selection effect. We now examine the possible effects of defendants choosing to reject bond offers and post bail personally.

Because posting one's own bail is generally cheaper then paying bond fees when the defendant intends to appear, it is reasonable for a bond dealer to infer that affluent defendants would want to use a bond dealer only if they are considering flight. ${ }^{164}$ Thus, any defendant who has sufficient assets to post bond personally and yet chooses to go to a bond dealer is immediately suspect. This heightened tendency of high-risk defendants to choose bond dealers over personally posting bail is called "adverse selection."

The impact of adverse selection is depicted in Figure 6, in which the flight schedule for a particular class of defendants is shown in relation to the various statutory and wealth constraints previously examined in Figure 4. The flight schedule for bail amounts to the right of defendants' posting wealth constraint are unaffected by adverse selection because bond dealers know that for these bail amounts this class of defendants does not have the option of posting bail personally. However, the adverse selection effect is visible in Figure 6 for bail amounts less then the defendants' wealth, i.e., to the left of the posting wealth constraint, where defendants could afford to post bail themselves. For these lower bail amounts, defendants choosing to post their own bail are less likely to flee because their own money is at risk. As for defendants seeking bond dealer services when they could post their own bail, bond dealers may rationally assume that such defendants have a higher propensity to flee. Dealers are therefore likely to demand higher rates of these defendants. The adverse selection effect therefore produces two different rate schedules for bail amounts that fall below defendants' wealth, as depicted in Figure 6.

This adverse selection effect might explain why, in our bailbonding sample, minority defendants received lower rates than whites. Suppose that white defendants are wealthier and therefore more likely to be able to post bail themselves without using a bond dealer. Then a white defendant's decision to hire a bond dealer, rather than post his own bond, is more likely to signal a tendency to jump bail. ${ }^{165}$ As a result, bond dealers may charge whites higher rates. Since minority defendants are less likely to be able to self-post, a greater proportion of those who do not intend to flee will seek bond dealers' services.

164. Defendants who intend to flee would naturally prefer to pay the nonrefundable fee to avoid having to post and forfeit the much higher bail amount.

165. It is not clear how courts should fulfill their statutory mandate to reasonably assure appearance if adverse selection is of concern. Suppose that judges face 100 defendants, each with and the flight schedule depicted in Figure 6. Suppose further that the judge knows that historically $50 \%$ of these defendants will use bond dealers if bail is set below their individual wealth. If the maximum acceptable flight probability is $8 \%$, should the judge set bail just above the defendants' wealth (to insure that no released defendant has more than an $8 \%$ probability of flight) or should the judge set bail below their wealth (to insure that the average defendant has an $8 \%$ probability of flight)? If the statute mandates the former interpretation, then adverse selection should not be a concern. We assume, however, that the latter interpretation is justufied and that the adverse selection effect could theoretically arise even among judges who legitimately attempt to induce a uniform probability of appearance. 
FIGURE 6

Adverse Selection Can Increase the Rates Charged When the Bail Amount Is Less than Defendant's Cash Wealth

Flight schedule for defendants who do not post their own bail

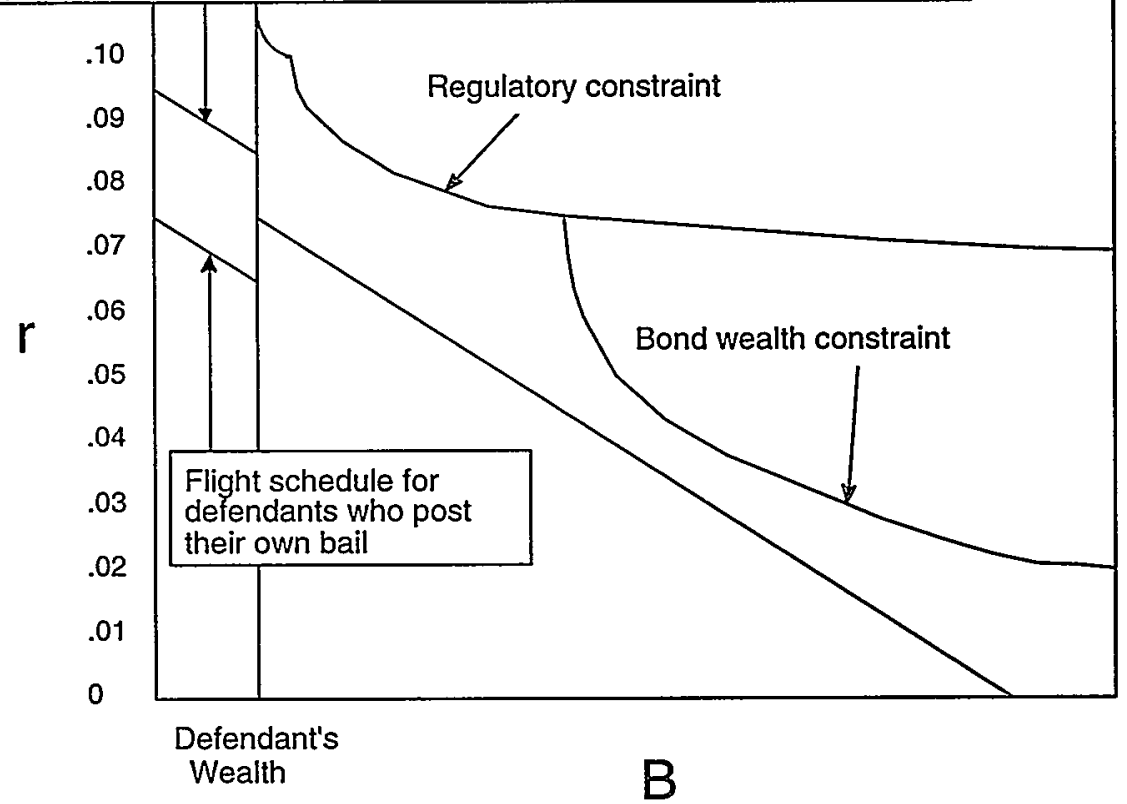

Consequently, the "average" expected flight probability for a minority member would be lower.

As with the jail selection effect, we are concerned that adverse selection might explain the racially disparate rates. Table 6 indicates that in 11 percent of the cases where judges require bail, defendants choose to post bail personally, and that whites are twice as likely to self-post as are blacks. Adverse selection, however, should not be expected to cause racially disparate bond rates for bail amounts where bond dealers might have confidence that white and minority defendants can either both afford or both not afford their own bail. But contrary to this expectation, we find that minority defendants pay lower rates even for bail amounts less than $\$ 1000$ or more than $\$ 5000$. As with the jail selection effect, we conclude that adverse selection seems an unlikely explanation for the full range of racial disparities in bond rates.

To summarize, the preceding section set forth what we think are the most critical nondiscriminatory explanations for our findings. We laid out the three major assumptions on which our conclusions depend, and tested them against these nondiscriminatory alternatives. While we uncovered inconsistencies and weaknesses in some of these alternative explanations, we continue to approach our original assumptions of proportionality, equalization, and sample selection with caution and a fair amount of skepticism. 


\section{Harnessing the Market in the Bail Setting Process}

If racial discrimination in bail setting is indeed prevalent, what can be done to mitigate its effect? In this Part, we consider a somewhat unorthodox proposal to harness the competitive forces of the bail bond market to produce an auction system of setting bail. ${ }^{166}$ Determining the size of bail by private auction would substantially reduce the influence of judges in setting bail. While we ultimately reject the proposal, our analysis of bond dealer auctions forces us to reevaluate our assumptions about market competition. If we trust market competition as a premise for our finding of judicial discrimination, then we must examine why we do not trust competition enough to allow market forces to set bail.

The auction mechanism would allow bond dealers' competitive bids to determine a defendant's bail. The proposed auction mechanism would operate as follows: Imagine that lawmakers want to ensure that defendants are released on bail only if there is no more than a 10 percent chance they will fail to appear. Bond dealers who wished to compete for a chance to write a bond for a particular defendant would enter a bid for the nonrefundable fee, and the lowest bid would win the right to bail the defendant. The crucial feature of this proposed system is that the bond dealer who wins the bid would have to pay 10 times the winning bid if the defendant failed to appear. ${ }^{167}$

Because lower bail amounts induce higher probabilities of flight, a bond dealer would want to avoid entering too low a bid. If, for example, bond dealers believed that a particular defendant had the flight schedule depicted in Figure 1 , no bond dealer would bid below $\$ 1500 .{ }^{168}$ In a perfectly competitive market, bond dealers would bid down the asking fee until there was exactly a 10 percent probability of flight, thus producing the legislative goal.

However, several considerations lead us to doubt that a low-bid auction would have this desired effect. First, defendants would have a tremendous incentive to make hidden side-payments to bond dealers to induce lower bids. For instance, in the previous example where the equilibrium fee bid was $\$ 1500$, the defendant might offer the bond dealer a $\$ 600$ bribe in order to induce the bond dealer to make a $\$ 50$ bid. The bond dealer would make $\$ 650$ from the bribe and the fee and yet have only $\$ 500$ at risk. Meanwhile, the defendant would reduce her costs of making bail from $\$ 1500$ to $\$ 650.169$

166. This idea was originally suggested to us by Professor Stephen G. Marks.

167. More generally, if the maximum allowable probability of flight were $q$, then the auction mechanism should mandate that the bond dealer forfeit [fee/q].

168. Under that flight schedule, a $\$ 1000$ bid would be unprofitable because it would expose a bond dealer to a $15 \%$ chance of a $\$ 10,000$ forfeiture. The bond dealer would have an expected cost of $\$ 1500$ which is higher than the bail fee of $\$ 1000$. In contrast, a $\$ 1500$ bid would expose a bond dealer to a $10 \%$ chance of a $\$ 15,000$ forfeiture, which generates the competitive zero-profit equilibrium.

169. This side-payment problem could be mitigated to a certain extent by adopting a second-bid auction structure, wherein the bond dealer with the lowest bid also receives a fee equal to his bid, but is forced to risk forfeiting ten times the second lowest bid. This second-bid alternative, at a minimum, would force the defendant to make side-payments to two bond dealers in order to induce an artificially low bid.

Second-price auctions have been widely analyzed in the economic theory of auctions and have been used in several market contexts. See, e.g., James D. Dana, Jr. \& Kathryn E. Spier, Designing a Private 
Second, while it is plausible to argue that higher bail amounts deter flight by inducing greater ex ante monitoring and ex post search (indeed, we have estimated downward sloping flight schedules in the Appendix in Table 8), the low-price auction mechanism tests our faith in the deterrence effect of bail. There is reason to doubt the assumption that lower auction bids would induce higher probabilities of flight. ${ }^{170}$ Even without side payments, bond dealers might well have an incentive to substantially decrease their bids for a large class of defendants who, regardless of bail, are relatively likely to appear in court. The possibility that bond auctions would produce low fees for a large class of defendants is not an embarrassment for the proposal, however. For this class of defendants, an auction system would actually produce more equitable results than the current system, which now increases the costs of pretrial release without deterring flight. ${ }^{171}$

Our biggest concern with a private auction for bail is not that bids will be too low but that they will be too high. Bond dealers may have the traditional incentive of auction competitors to collude and fix bids to increase the size of their fees. While competition is the traditional antidote to collusion, we fear that the market structure of cities such as New Haven (and certainly those of smaller towns) is not sufficiently competitive to make collusion impossible.

These visceral concerns about the competitiveness of the bail bond market raises troubling questions about our original results. If bail does not deter flight and bail bond markets are insufficiently competitive, our inference of discrimination may not be valid. Our market test of discrimination should not by itself form the basis for this kind of radical market-based reform.

\section{CONCLUSION}

In this paper, we have used data on the pricing of bond dealers' fees to assess whether judges discriminate on the basis of race or gender in setting bail. Our market test for race discrimination represents an attractive alternative to traditional regressions, which infer disparate racial treatment from unexplained residuals produced by multivariate regression studies. Because the traditional approach requires controlling for all variables that are possibly related to the probability of flight, this approach is often vulnerable to alternative explanations of the regression results based on omitted variable bias.

Industry: Government Auctions with Endogenous Market Structure, 53 J. PuB. Econ. 127 (1994) (suggesting that government agencies use second-bid auctions in allocating production rights); Gabrielle Demange, David Gale \& Marilda Sotomayor, Multi-Item Auctions, 94 J. PoL. Econ. 863 (1986) (contending that dynamic second-bid auctions may often result in prices approximating the minimum price equilibrium).

The possibility that defendants may bribe bond dealers is a serious concern, but before rejecting the auction mechanism on this ground we would need to compare the relative susceptibility of police, bail commissioners, prosecutors, and judges to the same type of bribery abuse under the current system.

170. As discussed at note 9 supra, several scholars have argued that bail does not deter flight.

171. Moreover, the auction mechanism could deter arbitrarily small fee bids by mandating a minimum forfeiture amount. In the end, the qualified evidence of discrimination that we have presented militates toward reducing judicial discretion in bail setting and instituting a more standardized procedure based on relatively rigid guidelines. 
Our analysis of bond dealers' pricing behavior eliminates the need to control for all relevant variables because bond dealers are able to observe and price everything about a defendant's flight propensity that the courts observe. Our analysis of the bond rates indicates that bail setting produces lower probabilities of flight among minorities. This is inconsistent with the statutory mandate that bail be set to limit flight probability to a constant maximum level for all bailees.

Our bond rate regressions, by themselves, do not provide credible evidence that courts engage in disparate racial treatment. However, unlike traditional regression analysis, our market test does provide evidence that bail setters in our sample used criteria inconsistent with the statute-criteria which disproportionately burden minority males. Specifically, the statistically significant tendency of bond dealers to charge lower bond rates to minority males shows (1) that courts increase bail for some characteristic unrelated to defendant flight propensity; and (2) that minority male defendants are most likely to have this characteristic.

These inferences provide the two core elements of a traditional disparate impact case: a showing that a criterion has a disparate impact and a showing that that criterion does not further legitimate goals of the decisionmaker. ${ }^{172}$ Normally, these two elements require different kinds of evidence, but our rate regression provides evidence of both elements in a single test. The market test represents an important methodological innovation not only because of its unified nature, but also because it is the first regression-based test that remains valid even when there are omitted variables. Our market evidence shifts the grounds of the debate away from the traditional arguments about omitted variable bias.

Our test, however, is premised on three crucial assumptions, whose validity is difficult to demonstrate. We have shown that the failure of any of these assumptions might give rise to numerous nondiscriminatory explanations for our results. We are most confident of our assumption that the only legitimate criterion for bail setting under the Connecticut bail-setting statute at the time our data were collected was to create equal flight probabilities for defendants charged with offenses of equal severity. Although courts might reasonably demand a higher probability of appearance for more serious crimes (indeed we found strong empirical evidence of this tendency), we showed that minority males are charged significantly lower bond rates than white males even after controlling for offense severity.

The proportionality and sample selection assumptions do not stand on equally strong footing. Our assumption that the bond rates are proportional to the probability of flight could fail for several reasons which we explored in detail. Most basically, bond markets may not be sufficiently competitive to drive bond fees to equal bond dealers' expected costs. Even though we found significant evidence of competition in the New Haven bond market, bond dealers may have discretion to charge higher fees to defendants who have poor

172. See, e.g., Wards Cove Packing Co., Inc. v. Atonio, 490 U.S. 642, 656-59 (1989). 
information or lack opportunities to search for lower bids - and these defendants may be disproportionately white. And even if the market fees reflect bond dealers' costs, it is possible that costs unrelated to the probability of disappearance may undermine the correlation of bond rates and flight risk. In the final analysis, however, we are still confident that the probability of flight is a major component of a bond dealer's expected cost and therefore a major determinant of a bond dealer's fee.

We also examined the possibility that the selection process by which defendants remain in jail or post bond personally distorts our data. If, for example, only low flight-risk minorities can afford bond dealer fees, or if bond dealers infer that wealthier whites who seek bail bonds are higher risks, then the sample of defendants on which we based our results would not be representative of the entire population of defendants who receive bail as a condition of release. While we have argued that disparate rates persist even for bail amounts where sample selection is less likely, the possibility of selection bias remains a concern, further qualifying our confidence in the rate regression.

While we have tried to interpret the rate regression cautiously, we should not overlook the startling nature of our results. We may have uncovered one of the only markets in the United States in which minorities pay lower prices. ${ }^{173}$ While price discrimination based on ability to pay can theoretically create favorable pricing for minorities, researchers have never been able to document its existence. ${ }^{174}$ The uniqueness of the result itself suggests a nonmarket cause.

A more direct test of discrimination would explicitly measure the likelihood of flight for various types of defendants. If we had direct evidence that minority men had a higher probability of appearance, we could draw stronger inferences of an unjustified disparate impact. However, in the absence of such data, we have relied on a classic economic axiom: In competitive markets, price is a good proxy for expected cost. This insight permits us to evaluate how bond dealers price the risk of flight-the major cost of providing bail bonds.

Our market test is an example of reactive institutional analysis, assessing the operation of one institution by evaluating the reactions of another institution. ${ }^{175}$ For the secondary reactions to be illuminating, one needs a predictive theory about how the reactive institution will behave. This paper has strongly relied on the premise that competition forces bond dealers to price the probability of a defendant's flight. While it might seem that this methodology could only be used under the unique circumstances of bail setting, this kind of market analysis might also apply to a broad variety of secondary markets for

173. Nonmarket pricing in the form of educational scholarships and certain housing prices depressed by "block busting" or white flight might provide other examples.

174. To the contrary, wealth effects tend to disproportionately disadvantage minorities. See, e.g., David Caplovitz, The Poor Pay More (2d ed. 1967); Ayres, supra note 15.

175. In the state corporate law context, one of the authors has explored how the reactions of courts to legislative initiatives (and the reactions of legislatures to common-law decisions) can be used to assess the race-to-the-top and common-law efficiency theories. Ian Ayres, Judging Close Corporations in the Age of Statutes, 70 WASH. U. L.Q. 365 (1992). 
securitized assets. ${ }^{176}$ For example, if banks discriminate against minorities in making house or car loans, we might expect that loans would only be made to minorities with lower probabilities of default than average white debtors. If this were true, competition should cause secondary purchasers of securitized "paper" to pay a premium for minority loans. ${ }^{177}$ A finding that the secondary market pays more for minority paper may indicate that the primary lenders used lending criteria that have an unjustified and disparate impact on minorities.

In this paper, we have not attempted to explain why courts might discriminate on the basis of race. This is in part because our results cannot identify conscious discrimination, only that courts use unjustifiable criteria that disproportionately burden minority males. Racial animus is only one possible example of an unjustified criterion. Moreover, because police, bail commissioners, and judges all set bail, it is difficult to identify the source of the racial disparity. Following Gary Becker's insight that employment discrimination could be caused by customer animus, ${ }^{178}$ it is also possible that judicial discrimination is caused by voter animus. If voters disproportionately punish judges when minority defendants flee or engage in pretrial misconduct, then elected judges may raise the size of minority bail to reduce the possibility of "Willie Horton"style attacks. ${ }^{179}$ This voter animus theory would probably demand a more informed voter and a smaller incumbency advantage than we typically observe, but the theory illustrates the variety of possible causes of bail discrimination. ${ }^{180}$

Given the variety of alternative theories that might at least theoretically explain our findings, this study cannot be taken as a definitive demonstration of race discrimination. Several of these alternative explanations, however, are themselves capable of empirical refutation (and where possible we have provided some evidence bearing on their validity). The results of this study can thus be regarded as a first step toward analyzing the bail system using market data. Given the daunting problems with traditional race regressions, we believe that we have outlined a promising new approach to analyzing the bail system. Our market-based approach used in conjunction with traditional methodologies offers the possibility of a more powerful test of discrimination. At the very least, our results lend added empirical support to widespread concerns that the state of Connecticut in setting bail may discriminate on the basis of race. Policymakers should continue to investigate whether the bail setting process unduly disadvantages minority defendants.

176. For an overview of the world of securitized assets, see, e.g., STEVEN L. SCHWARCZ, STRUCtured Finance: A Guide to the Principles of Asset Securitization (2d ed. 1993).

177. While it may seem intuitively unlikely that the Fannie Mae market (or its automobile counterpart) would pay more for loan packages which include disproportionate numbers of minority loans, we thought it no more likely that we would find evidence that the bail bond market favors minority defendants prior to attempting this study. Our results are all the more surprising because they confound prior intuitions about market preferences.

178. BECKER, supra note 45 , at 57 .

179. During the 1988 presidential campaign, an independent organization supporting Vice President George Bush used Willie Horton, a black convict, as a symbol of the dangers of the parole system.

180. Racial animus by decisionmakers might be weakly inferred by testing whether white decisionmakers discriminate more than minority decisionmakers. See Ayres \& Siegelman, supra note 15. We cannot perform this test in our sample, however, because all of the judges in our sample were white. 
Appendix A: Ex Ante Monitoring and Ex Post Search

In the text of this article, we developed a simple model of bail pricing which accounted for the effects of both collateral and the bond forfeiture rate. In the model that we develop here, we suppress these aspects of bond pricing (by assuming that $C=0$ and that $f=1)^{181}$ and instead examine the effects of ex ante monitoring and ex post search. Modeling the effects of monitoring and search allows us to demonstrate (1) that higher bail amounts can reduce the probability of flight and (2) that monitoring and search costs can potentially undermine the proportionality between the probability of flight and the bond rate.

\section{A. Demonstrating How Monitoring and Search Can Deter Flight}

In this revised model, the expected profits $(I T)$ of a bond dealer can be expressed as:

$$
\Pi=R-M-p S-p\left(1-p_{r}\right) B
$$

where:

$B$ = the bail amount;

$R=$ the bail bond fee;

$M=$ the costs of monitoring the defendant to insure that she appears at trial;

$p=$ the probability that the defendant will flee;

$S=$ the costs of searching if the defendant flees; and

$p_{r}=$ the probability that the defendant will be recaptured if she flees.

The bond dealer bears the cost of monitoring each defendant plus the cost of search (if a defendant flees) plus the cost of bond forfeiture (if the defendant flees and is not recaptured). The bond dealer must choose how much to monitor and search. We assume that increased monitoring decreases the probability of flight $(\delta p / \delta M<0)$ and that increased search increases the probability of recapture $\left(\delta p_{r} / \delta S>0\right)$, but that there are diminishing returns to each type of expenditure $\left(\delta^{2} p / \delta M^{2}<0, \delta^{2} p_{r} / \delta S^{2}<0\right)$. We can derive the profit maximizing amount of monitoring and search by examining the first order conditions (FOC) for profit maximization. ${ }^{182}$ The FOC for monitoring is:

$$
1=-(\delta p / \delta M)\left[S+\left(1-p_{r}\right) B\right]
$$

and the FOC for search is:

$$
1=\left(\delta p_{r} / \delta S\right) B .^{183}
$$

181. Incorporating collateral and forfeiture rates effects into this model does not qualitatively change the results. As long as the fraction of bail taken as collateral and the portion of bail that is forfeited remain constant, the proportional relationship between the bond rate and the probability of flight will not be affected.

182. The first order conditions for monitoring and search are derived by taking the derivative of profits with respect to $S$ and $M$ and setting this expression equal to zero.

183. Although expectation of (ex post) search reduces the (ex ante) probability of flight, bond dealers cannot credibly commit to a level of search until after the defendant flees. Accordingly, the bond dealer chooses the level of search that minimizes $\left[S+\left(1-p_{r}\right) B\right]$. The indirect effect of search on 
Each of these optimizing conditions can be interpreted to show that it will be profitable for a bond dealer to increase the amount of monitoring and searching until the marginal cost (expressed on the left-hand side of each equation) equals the marginal benefit (expressed on the right-hand side).

Most important, these FOCs imply that, as the bail amount increases, bond dealers will find it in their interest to increase both monitoring and search efforts. Increasing the bail increases the marginal benefit of these activities, and bond dealers will increase their expenditures until the marginal impacts on the probabilities of flight $(\delta p / \delta M)$ and recapture $\left(\delta p_{r} / \delta S\right)$ are reduced to fulfill the first order conditions. Increased monitoring directly reduces the probability of flight, because the bond dealer keeps closer tabs on the defendant's whereabouts $[\delta p / \delta M<0]$; increased search in the event of flight indirectly reduces the probability of flight, because defendants know that there is an increased probability that they will be recaptured (and received an enhanced punishment) $\left[\left(\delta p / \delta p_{r}\right)\left(\delta p_{r} / \delta S\right)<0\right]$.

\section{B. Investigating the Effects of Monitoring and Search Costs on the Bail Rate}

The bail rate in a competitive (zero-profit) equilibrium can be derived by setting the profit equation equal to zero and dividing the equation by $B$. Solving the resulting expression in terms of $r$ yields:

$r=p\left[1-p_{r}+(S / B)\right]+(M / B)$.

The monitoring effect $[M / B]$ and search effect $\left[-p_{r}+(S / B)\right]$ on the competitive bond rate create two independent sources of concern because each of these two terms could vary as the bail amount changes. If either one varies, the bond rate might not remain proportional to the probability of flight as we assumed for our discrimination test.

Our initial assumption of proportionality (between $r$ and $p$ ) will still hold if we assume both that ex post search costs are negligible and that ex ante monitoring expenditures are proportional to the amount of bail. The former assumption may well be justified. As an empirical matter, the search effect is not likely to have a large impact on the bail rate; bond dealers have reported that ex ante monitoring is a much more important determinant of defendants' appearance than ex post efforts at recapture. The simplifying assumption that $S=0$ may therefore approximate current dealer practices. The latter assumption is akin to saying that bond dealers spend proportionately more time keeping tabs on defendants as bail amounts increase. This assumption can be expressed algebraically as: $M=\beta B$. Making these assumptions, we can reexpress the market bail rate as:

$$
r=p\left(1-p_{r}+\beta\right)
$$

in which $r$ is once again proportional to the probability of flight regardless of bail amount.

the probability of flight $\left[\left(\delta p / \delta p_{r}\right)\left(\delta p_{r} / \delta s\right)\right]$ does not affect the bond dealer's choice. Because the level of search is determined after the fact, the bond dealer has already determined that the defendant has disappeared $(p=1)$. 


\section{Appendix B: Estimating Rate Schedules}

Estimating the relationship between bail amounts and the bond rates is difficult because both bail amounts and bond rates are dependent on flight risk. In econometric parlance, both the bail amount and the flight risk are "endogenous" variables. In order to obtain an unbiased estimate of the causal relationship running from bail amounts to bond rates (and, subsequently to flight risk) we must statistically control for the endogenicity of bail.

Endogenicity bias, if not controlled for, can result in an underestimate of the deterrence effect of bail. Because bail is based in part on flight factors that are observable to both the court and the bond dealers but not to the researcher, such factors should mitigate any true negative correlation between $r$ and $B .{ }^{184}$ Accordingly, we should expect that the endogenicity bias would cause simple ordinary least squares (OLS) regressions to understate the deterrence effect that increases in bail would have on the probability of flight. In mathematical terms, the endogenicity bias would cause us to underestimate $\delta r / \delta B$.

In the analysis below, we control for the endogenicity of bail by looking at the bail amounts set by different judges for similar defendants. If defendants are similarly situated, then interjudge differences in average bail amounts are unrelated to defendants' flight risks. These differences in bail are thus free from the flight risk endogenicity problem, and can therefore be used to identify the relationship between bail amounts $(B)$ and bond rates $(r)$.

This technique for estimating equations that have endogenous variables is called the "instrumental variables" technique. Intuitively, an "instrument" provides a truly exogenous source of variation in the data. By regressing the endogenous variable against a set of instruments, we can generate an exogenous proxy for the endogenous variable, which, in turn, can be fed into the original regression to obtain unbiased estimates. ${ }^{185}$

Table 7 reports the results of an ordinary least squares regression of log bail on judge identifiers and defendant and offense characteristics. As Table 7 indicates, judges do in fact tend to set bail at significantly different levels (for random sets of defendants). For example, two of the judges set bail 50.3 and 37.7 percent higher, respectively, than the baseline judges, after controlling for observable defendant and offense characteristics. 186 Therefore dummy variables for judge identification can be used to "instrument" for bail.

184. See GRIFFTHS ET AL., supra note 82, at 585-602.

185. For a rigorous explanation of this technique, see $i d$. at 458-65. The strategy of using interjudge differences in decisionmaking tendencies as instruments has been employed elsewhere. See, e.g., Joel Waldfogel, The Selection Hypothesis and the Relationship between Trial and Plaintiff Victory, (National Bureau of Economic Research Working Paper No. 4508, 1993, on file with the Stanford Law Review); Orley Ashenfelter \& Joel Waldfogel, Bargaining in the Shadow of the Judge: Empirical Tests (Apr. 24, 1993) (unpublished manuscript, on file with the Stanford Law Review).

186. These differences are particularly reliable since they are based on large numbers of cases. Judges 3 and 7 were assigned 164 and 184 cases, respectively. 
TABLE 7

Judge Effects on Bail

\begin{tabular}{|lll|}
\hline \multicolumn{3}{|c|}{ Log Bail Amount } \\
& coefficient & t-stat. \\
\hline CONST & $6.551^{*}$ & 25.64 \\
\hline Defendant & Characteristics \\
BM & $0.289^{*}$ & 3.80 \\
HM & 0.134 & 1.23 \\
WF & -0.091 & -0.61 \\
BF & 0.044 & 0.41 \\
HF & -0.282 & -1.16 \\
\hline Judge Identifiers & \\
Judge 1 & 0.051 & 0.27 \\
Judge 2 & 0.011 & 0.07 \\
Judge 3 & $0.503^{* *}$ & 3.51 \\
Judge 4 & 0.157 & 0.78 \\
Judge 5 & 0.057 & 0.34 \\
Judge 6 & 0.076 & 0.55 \\
Judge 7 & $0.377^{* *}$ & 2.66 \\
Judge 8 & 0.083 & 0.56 \\
Judge 9 & -0.024 & -0.12 \\
Judge 10 & -0.083 & -0.36 \\
Judge 11 & -0.002 & -0.01 \\
\hline $\mathrm{R}^{2}$ & 0.410 & \\
$\mathrm{~N}$ & 1118 & \\
\hline$*$ Significant at the 90\% level. \\
** Significant at the 95\% level. \\
Offense severity variables were included \\
in this regression but are not reported to \\
save space. & & \\
\hline & & \\
\hline
\end{tabular}


To estimate the position of various rate schedules, we estimated equations (3) and (4) by means of a three-stage least squares regression: ${ }^{187}$

$$
\begin{aligned}
& \ln B_{i}=\alpha_{b}+X_{i} \beta_{b}+\varepsilon_{b}, \\
& \ln r_{i}=\alpha_{r}+X_{i} \beta_{r}+\theta \ln B_{i}+\varepsilon_{r}
\end{aligned}
$$

Note that the only difference between these equations and equations (1) and (2) (in Section C of Part III) is the inclusion of $B_{i}$ in the rate equation. We will refer to equation (4) as the "rate schedule equation," since it estimates the rate charged for any bail amount.

Assuming that the bond rate is proportional to flight probability, the rate schedule shows how various characteristics affect the propensity of flight. ${ }^{188}$ In particular, the rate schedule allows us to test whether a defendant's race or gender affects her propensity to flee.

The parameter $\theta$ is the elasticity of rate paid with respect to bail amount. Because under our assumptions the rate paid is proportional to the flight probability, $\theta$ is also the elasticity of the flight probability with respect to bail amount. ${ }^{189}$

The results of these regressions appear in Table 8. As discussed in the text, ${ }^{190}$ the rate schedules for minority male defendants are not statistically different from those of white males (and the rate schedules for black and Hispanic females are significantly lower than those of white males). This suggests that minority defendants do not have a higher propensity to flee. Judges wishing to equalize the probabilities of flight would therefore not have to set higher bail amounts for minority men than for white men.

187. Three stage least squares regression (3SLS) amounts to nothing more than using instrumental variables to help estimate a system of seemingly unrelated regressions (SUR). See note 82 supra for a brief discussion of the SUR technique.

188. Under the proportionality assumption, the rate schedule is proportional to the flight schedule such that variables that shift the latter would also shift the former. Shifts in the flight schedule reflect different flight propensities.

189. The elasticity of an endogenous variable $Y$ with respect to some endogenous variable $X$ is simply the percentage change in $Y$ induced by a change in $X$ divided by the percentage by which $X$ changes. For small changes in $\mathrm{X}$, this is $\delta \mathrm{Y} / \delta \mathrm{X}(\mathrm{X} / \mathrm{Y})$, which is equivalently $\delta \ln (\mathrm{Y}) / \delta \ln (\mathrm{X})$. From the rate schedule equation in the text, $\theta$ is $\operatorname{simply} \delta \ln (r) / \delta \ln (B)$ and therefore $\theta$ is the elasticity of the bond rate with respect to the bail amount. Additionally, under the proportionality assumption that $r=\alpha p$, the elasticity of the bond rate with respect to the bail amount is the sum of the elasticity of $\alpha$ and the elasticity of flight probability $p$ (both with respect to bail amount $B$ ). Since $\alpha$ is constant, its elasticity with respect to $B$ is zero-so the bond rate elasticity equals the flight probability elasticity.

190. See text accompanying notes 104-107 supra. 
TABLE 8

Bail Equation and Rate Schedule

(Estimated by $3 S L S^{\mathrm{a}}$ )

\begin{tabular}{|c|c|c|c|c|}
\hline & \multicolumn{2}{|c|}{ Log Bail Amount ${ }^{\mathrm{a}}$} & \multicolumn{2}{|c|}{ Log Rate Paid } \\
\hline & coeff. & t-stat. & coeff. & t-stat. \\
\hline Constant & $6.673^{* *}$ & 29.85 & $0.900^{* *}$ & 2.33 \\
\hline \multicolumn{5}{|c|}{ Defendant Characteristics } \\
\hline Black Male & $0.352^{* *}$ & 4.67 & -0.002 & -0.06 \\
\hline Hispanic Male & $0.194^{*}$ & 1.79 & -0.046 & -1.05 \\
\hline White Female & -0.057 & -0.38 & 0.000 & 0.01 \\
\hline Black Female & 0.075 & 0.71 & $-0.075^{*}$ & -1.78 \\
\hline Hispanic Female & -0.234 & -0.96 & $-0.191^{* *}$ & -1.99 \\
\hline \multicolumn{5}{|l|}{ Offense Severity } \\
\hline Class A or B Fel. & $1.587^{* *}$ & 6.23 & $0.650^{* *}$ & 4.85 \\
\hline Class C or D Fel. & $0.926^{* *}$ & 4.13 & $0.448^{* *}$ & 4.39 \\
\hline Class U Felony & $0.683^{* *}$ & 3.43 & $0.291^{* *}$ & 3.35 \\
\hline Class A or B Misd. & -0.207 & -0.97 & 0.053 & 0.63 \\
\hline Class $C$ or D Misd. & -0.300 & -1.28 & -0.012 & -0.13 \\
\hline \multicolumn{5}{|l|}{ Offense Category } \\
\hline Assault & 0.062 & 0.67 & $0.078^{* *}$ & 2.16 \\
\hline Failure to Appear & -0.118 & -0.93 & -0.004 & -0.07 \\
\hline Larceny & -0.043 & -0.37 & 0.061 & 1.32 \\
\hline Drug & $0.519^{* *}$ & 4.03 & $0.239^{* *}$ & 4.10 \\
\hline Gun & $0.339^{* *}$ & 2.20 & $0.251^{* *}$ & 3.97 \\
\hline Disorderly Conduct & $-0.367^{* *}$ & -3.50 & $-0.078^{*}$ & -1.70 \\
\hline Natural Log of Bail & & & $-0.527^{* *}$ & -9.32 \\
\hline $\mathbf{N}$ & 1118 & & 1118 & \\
\hline $\mathrm{R}^{2}$ & 0.387 & & 0.356 & \\
\hline \multicolumn{5}{|c|}{${ }^{* *}$ Significant at the $95 \%$ level. } \\
\hline $\begin{array}{l}{ }^{\text {a }} \text { All right-hand side } \\
\text { exogenous. Judge d }\end{array}$ & riables exce & $\begin{array}{l}t \log \text { bai } \\
\text { d as inst }\end{array}$ & $\begin{array}{l}\text { are treated a } \\
\text { uments. }\end{array}$ & \\
\hline
\end{tabular}


HeinOnline -- 46 Stan. L. Rev. 1048 1993-1994 